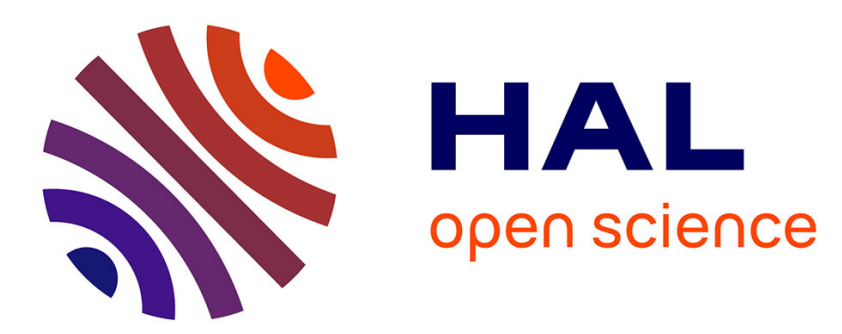

\title{
Evaluating the Effect of Ownership Status on Hospital Quality: The Key Role of Innovative Procedures \\ Laurent Gobillon, Carine Milcent
}

\section{To cite this version:}

Laurent Gobillon, Carine Milcent. Evaluating the Effect of Ownership Status on Hospital Quality: The Key Role of Innovative Procedures. Annals of Economics and Statistics, 2016, 121-122, pp.161-186. 10.15609/annaeconstat2009.121-122.161 . halshs-01509624

\section{HAL Id: halshs-01509624 \\ https://shs.hal.science/halshs-01509624}

Submitted on 19 Dec 2018

HAL is a multi-disciplinary open access archive for the deposit and dissemination of scientific research documents, whether they are published or not. The documents may come from teaching and research institutions in France or abroad, or from public or private research centers.
L'archive ouverte pluridisciplinaire HAL, est destinée au dépôt et à la diffusion de documents scientifiques de niveau recherche, publiés ou non, émanant des établissements d'enseignement et de recherche français ou étrangers, des laboratoires publics ou privés. 


\title{
Evaluating the effect of ownership status on hospital quality: The key role of innovative procedures
}

\author{
July $2014^{1}$ \\ Laurent Gobillon $^{2} \quad$ Carine Milcent ${ }^{3}$
}

\begin{abstract}
Mortality differences between university, non-teaching public and for-profit hospitals are investigated using an exhaustive French administrative dataset of patients admitted for heart attack. Our results show that innovative procedures play a key role in explaining the effect of ownership status on hospital quality. When age, sex, diagnoses and co-morbidities are held constant, the mortality rates in for-profit and university hospitals are similar, but they are lower than in non-teaching public hospitals. When additionally controlling for innovative procedures, the mortality rate is higher in for-profit hospitals than in the two groups of public hospitals. This suggests that the quality of care in for-profit hospitals relies on their capacity to perform innovative procedures. A counterfactual exercise shows that if patients in non-teaching public hospitals were treated with innovative procedures following the assignment rule of for-profit hospitals rather than that of non-teaching public hospitals, their probability of death after a duration of 7 days would be 1.8 points lower.
\end{abstract}

Keywords: hospital performance, innovative procedures, stratified duration model JEL code: I12, I18

\footnotetext{
${ }^{1}$ We are grateful to Xavier D’Haultfoeuille, Jonathan Skinner, the participants of ECHE 2012, and three anonymous referees for useful comments and discussion.

${ }^{2}$ Corresponding author. INED, PSE, CEPR and IZA. INED, 133 boulevard Davout, 75980 Paris Cedex. Email: laurent.gobillon@ined.fr. Tel: 01560620 16. Webpage: http://laurent.gobillon.free.fr.

${ }^{3}$ PSE (CNRS-EHESS-ENPC-ENS), 48 boulevard Jourdan, 75014 Paris. Email: milcent@pse.ens.fr. Webpage: http://www.pse.ens.fr/milcent/index.html.
} 


\section{Résumé}

Les différences de mortalité entre les centres hospitalo-universitaires, les hôpitaux publics non enseignants et les hôpitaux privés à but lucratif sont étudiées en utilisant une base de données administrative française sur les patients admis pour une crise cardiaque. Nos résultats montrent que les procédures innovantes jouent un rôle majeur dans l'explication de l'effet du statut hospitalier sur la qualité des soins. A âge, sexe, diagnostiques et comorbidités données, les taux de mortalité des hôpitaux privés à but lucratif et des centres hospitalo-universitaires sont similaires, mais ils sont plus faibles que celui des hôpitaux publics non enseignants. Lorsqu'on raisonne en plus à actes innovants donnés, le taux de mortalité est plus élevé pour les hôpitaux privés à but lucratif que pour les deux autres types d'hôpitaux. Cela suggère que la qualité des soins dans les hôpitaux privés à but lucratif repose sur leur capacité à faire des actes innovants. Un exercice contrefactuel montre que si les patients admis dans des hôpitaux publics non enseignants étaient traités selon les modalités des hôpitaux privés à but lucratif plutôt que celles des hôpitaux publics non enseignants, leur probabilité de décès après une durée de 7 jours serait de 1.8 points plus faible. 


\section{Introduction}

In many countries, there is debate among politicians and scholars about the extent to which hospital ownership status influences hospital performance. An extensive literature has developed in the US to compare the performance of for-profit and not-for-profit hospitals (Sloan, 2000; Kessler and McClellan, 2001). In parallel, other research has focused on the diffusion of new efficient technologies which have spread since the 1990s and improved hospital outcomes (Cutler and McClellan, 1996; Heidenreich and McClellan, 2001; Ho, 2002; Bradley et al., 2005; Skinner and Staiger, 2009). Our paper shows the important role of innovative procedures in explaining the effect of ownership status on hospital quality. European countries usually have a mix of public hospitals that are required to treat all patients, and of for-profit hospitals which select their patients. Public hospitals have a limited global budget funded by the government, and the total cost of disposable medical supplies is charged to this budget. Because of their research and teaching activities, university hospitals have a larger budget than non-teaching public hospitals, so they can perform more innovative procedures. By contrast, for-profit hospitals are most often considered to be profit-maximizing entities and each unit of disposable medical supply used for a procedure is fully reimbursed. In France, for-profit hospitals have no research or teaching activities.

In this paper, we address the issue of whether patients are treated better in for-profit hospitals than in public hospitals, and whether this is driven to some extent by differences in the use of innovative procedures as the funding system varies across hospital ownership statuses. More precisely, we study the in-hospital mortality differences between French public and for-profit hospitals for patients admitted for a heart attack. ${ }^{4}$ In contrast with other studies, we distinguish university hospitals from non-teaching public hospitals, as they have different health practices and different budgets. We assess to what extent mortality differences can be explained by differences in case-mix and use of innovative procedures. Our empirical strategy relies on the estimation of a very flexible duration model with hospital-specific baseline hazards on a French exhaustive administrative dataset. Once this model is estimated, we use an original approach to build counterfactuals of mortality rates in non-teaching public hospitals when patients receive treatment according to the assignment rules of for-profit hospitals. In particular, our approach

\footnotetext{
${ }^{4}$ In France, there are also not-for-profit hospitals funded as public hospitals but run as private ones. They treat only $4.8 \%$ of heart attack patients and are excluded from our analysis for simplicity.
} 
takes into account the observable characteristics of patients when assigning treatment to patients. The literature is plagued with two types of selection issues. First, the type of insurance can vary across patients, as is the case in the US. There is a selection effect if patients with better insurance coverage are admitted to a specific type of hospital. To overcome this problem, authors focus on patients with the same insurance (McClellan and Staiger, 2000), or study countries where there is universal coverage, such as Taiwan (Lien, Chou and Liu, 2008). In France, there is universal coverage as a single payer reimburses costs at a flat rate for all patients.

A selection bias also appears when patients with the lowest chances of survival due to comorbidities and secondary diagnoses tend to be admitted to or transferred from a specific type of hospital. In France, for-profit hospitals may refuse the sickest patients to maximize their profit (as in-hospital deaths are costly and a hospital's reputation depends on its success statistics), whereas public hospitals are required to provide them with care. Non-teaching public hospitals may transfer the sickest patients because they do not have the equipment needed to treat them. We limit this bias in our study by controlling for a wide range of secondary diagnoses and propose suggestive robustness checks which show that our qualitative conclusions are not altered by a possible selection on remaining unobservables.

Our results show that when age, sex, diagnoses and comorbidities are held constant, the mortality rates in for-profit and university hospitals are similar, but they are lower than in non-teaching public hospitals. When additionally controlling for innovative procedures, the mortality rate is higher in for-profit hospitals than in the two groups of public hospitals. This suggests that the quality of care in for-profit hospitals relies on the capacity to perform innovative procedures. Our counterfactual exercise shows that if patients in non-teaching public hospitals were treated with innovative procedures (catheters, possibly with angioplasties and stents) following the assignment rule of for-profit hospitals rather than that of non-teaching public hospitals, their probability of death after a duration of 7 days would be 1.8 points lower.

The structure of the paper is as follows. Section 2 presents our exhaustive administrative dataset on patients' stays. Section 3 develops the empirical strategy used to compute the probability of death by ownership status, net of case-mix and innovative procedures. While section 4 presents the results, section 5 discusses the existence of unobserved patient heterogeneity as well as possible biases induced in the estimations. Section 6 gives the results of our counterfactual exercise and section 7 provides our conclusions. 


\section{Data}

We use the exhaustive data on stays in French hospitals provided by the "Programme de Médicalisation des Systèmes d'Information” over the 1998-2003 period. We select patients aged over 35 admitted for heart attack (i.e., acute myocardial infarction: AMI) to a university hospital, a non-teaching public hospital or a for-profit hospital.

We know the duration of stay and the type of entry: whether patients came from home or were transferred from another service or hospital. As we do not have any details on previous hospitalization for transferred patients, we focus on patients coming from home, who constitute $81.6 \%$ of the original sample. ${ }^{5}$ We end up with a sample of 325,760 patients in 1,020 hospitals, among whom $21.0 \%$ are in for-profit hospitals, $28.5 \%$ are in university hospitals and $50.6 \%$ are in non-teaching public hospitals. We also know the type of exit: death (8\%), home return (59\%), transfer to another service (2\%), to another acute care hospital (24\%) or to another type of hospital (7\%).

As we cannot follow patients when they are discharged, we study patients during their stay within the hospital. We focus on exits to death and treat all other exits as right-censored.

We have information on the age and sex of patients, as well as detailed information on comorbidities (i.e., pre-existing conditions), secondary diagnoses and treatment procedures. Detailed comorbidities and diagnoses are related to the way of life (smoking, alcoholism, obesity, hypertension), chronic health problems (diabetes, conduction diseases, history of coronary disease), disease complications (renal failure, heart failure), and site of heart attack (anterior, posterior, sub-endocardial, other).

Treatments include bypass surgery, which is a traditional procedure, and catheter, angioplasty and stent, which are more recent. All these procedures are designed to unblock the clogged section of the vein or artery that caused the heart attack. A bypass surgery reroute involves grafting a vein or artery taken from elsewhere in the body to bypass the blockage. A catheter is a thin tube inserted into a vein to facilitate injections and drips. Angioplasty consists of inflating a balloon catheter to crush a blockage and open up the blood vessel for improved flow. The stent is a spring-shaped prosthesis used alongside angioplasty to keep the artery dilated. This was the most innovative procedure in use during our period of study, and its use has increased over time.

\footnotetext{
${ }^{5}$ Patients transferred from another acute care hospital constitute $17.9 \%$ of the original sample and thus most of the discarded patients.
} 
For each hospital, we compute a non-parametric estimator of the survival function (the KaplanMeier estimator) for exit to death, while other types of exits are treated as censored. The probability of death is constructed for each hospital as one minus the survival function. It is then averaged by ownership status, weighted by the number of patients admitted to the hospital. Figure 1 shows the probability of death as a function of duration (in days) by ownership status. This probability is similar for for-profit and university hospitals, but is significantly higher for non-teaching public hospitals. ${ }^{6}$ For instance, the probability of death after 5 days is $4.2 \%$ for forprofit hospitals, $4.4 \%$ for university hospitals and $6.6 \%$ for non-teaching public hospitals, as shown in Table 1.

Descriptive statistics reported in Table 2 show that despite these disparities, the average duration before death is similar for for-profit and non-teaching public hospitals at 6.6 days. This contrasts with differences in the average duration before death for other types of exits across hospital statuses. Whereas transfer rates are very similar for for-profit and university hospitals, nonteaching public hospitals have a higher rate of transfers to other acute care hospitals, probably because they are less able to treat patients needing surgery. The average duration before this type of transfer is the shortest for non-teaching public hospitals at around 6.1 days, and is a bit longer for for-profit hospitals (6.5 days) and university hospitals (7.0 days). There are more disparities in the average duration before home return, as it reaches 9.5 days for non-teaching public hospitals but only 7.7 days and 7.4 days for university and for-profit hospitals, respectively. These disparities could be due not only to differences in healthcare, but also to the strategic behaviours of hospitals in the for-profit sector, which may try to avoid death in hospital by sending some patients back home quickly or may want to increase their turnover in order to increase profits. Indeed, patients occupying a bed without receiving any additional surgical procedure are not profitable.

\section{[ Insert Figure 1]}

[ Insert Table 1 ]

\footnotetext{
${ }^{6}$ We also conducted log rank tests to assess whether the profiles of probabilities of death are significantly different over the first 30 days of stay. As expected from the Figures, we find that probabilities of death are significantly different at the $1 \%$ level when comparing non-teaching hospitals with for-profit hospitals (statistic value: 21.6), as well as when comparing non-teaching hospitals with university hospitals (statistic value: 24.4 ). The equality cannot be rejected even at the $10 \%$ level when comparing university and for-profit hospitals (statistic value: 0.06 ).
} 
Table 2 also presents descriptive statistics by ownership status on demographic characteristics (full interactions between sex and age brackets), comorbidities, secondary diagnoses and procedures. In particular, for-profit and university hospitals both treat a smaller proportion of patients above age 80 than non-teaching public hospitals; they use more than twice as many catheters as non-teaching public hospitals (70\% vs. $28 \%$ ); and treatments with stents are more than three times more frequent ( $40 \%$ and $36 \%$ vs. $11 \%$ ).

We now propose an approach to assess whether the in-hospital mortality differences between forprofit, university and non-teaching public hospitals can be explained by differences in patients' characteristics and treatment procedures.

\section{Empirical strategy}

We present in this section the econometric approach used to compute the probability of death net of the effects of case mix and innovative procedures by ownership status. We also explain how counterfactuals can be derived.

\section{Model and estimation approach}

The empirical strategy is as follows. Let $i$ index the patient and $j(i)$ the hospital where patient $i$ is admitted. We specify the latent duration before death as a Cox model stratified by hospital. The hazard rate is given by:

$$
\lambda\left(t \mid X_{i}, j(i)\right)=\lambda_{j(i)}(t) \exp \left(X_{i} \beta\right)
$$

where $X_{i}$ includes the patient's characteristics (age, sex, comorbidities and secondary diagnoses) and the procedures, and $j(i)$ is the hospital in which individual $i$ is admitted. The vector of coefficients $\beta$ captures their effect on mortality, and $\lambda_{j}(t)$ is the hazard rate specific to hospital $j$, which is left completely unspecified. This allows considerable flexibility in the way hospitals may differ, in particular across ownership status. This specification is quite general, as it allows for hospital shocks that possibly correlate with patient variables that enter the hospital-specific baseline hazards. Biases in estimated coefficients and standard errors due to hospital shocks are thus avoided, whereas this is not the case for the standard Cox model. 
Exits other than death, that is to say transfers and home returns, are treated as exogenous censorship. In particular, this assumption is verified only if there is no unobserved heterogeneity affecting both exit to death and other exits. We discuss this assumption and provide robustness checks in Section V.

The parameters of patient variables are estimated by Stratified Partial Likelihood (Ridder and Tunali, 1999; Gobillon, Magnac and Selod, 2011). Denote by $\Omega^{j}(t)$ the set of patients at risk of dying in hospital $j$ after duration $t$. The probability of patient $i$ dying at duration $t$ conditionally on someone in his hospital dying at that duration is given by:

$$
\mathcal{L}_{i}(t)=\frac{\exp \left(X_{i} \beta\right)}{\sum_{n \in \Omega^{j(i)}(t)} \exp \left(X_{n} \beta\right)}
$$

Conditioning on the population at risk in the hospital (instead of the whole population at risk, as would be the case for the standard Cox model) cancels out the hospital-specific baseline hazard. As a consequence, there is no need for specifying the functional form of the hospital-specific baseline hazard. The stratified likelihood function is then given by the product of the probabilities for all the patients. Its maximization yields some estimates for the coefficients of patient variables denoted by $\hat{\beta}$.

We run a specification test of the proportional hazard model using the now standard approach proposed by Grambsch and Therneau (see for instance Lawless, 2003, for details). For each explanatory variable, residuals called Schoenfeldt residuals can be defined. In the case that the model is a Cox proportional hazard model, these residuals should not be correlated with duration at exit to death (for individuals for whom this exit is observed). We also perform a Hausman test to assess whether a stratified Cox model is needed instead of a standard Cox model with dummies for hospital statuses. This test can be conducted using estimated coefficients of patient variables (those for hospital status being excluded), because under the null assumption that the standard Cox model is verified by the data, estimators of coefficients obtained with non-stratified partial likelihood are consistent and efficient; those obtained with stratified partial likelihood are consistent. Under the alternative assumption that there is some unobserved hospital heterogeneity, estimators of coefficients obtained with non-stratified partial likelihood are not consistent; but those obtained by stratified partial likelihood still are. 
In a second step, it is possible to estimate the integrated baseline hazard of a given hospital $j$, given by $\Lambda_{j}(t)=\int_{0}^{t} \lambda_{j}(t) d t$ using the Breslow (1974)'s estimator:

$$
\hat{\Lambda}_{j}(t)=\int_{0}^{t} \frac{I\left(C^{j}(s)>0\right)}{\sum_{i \in \Omega_{j}(s)} \exp \left(X_{i} \hat{\beta}\right)} d N^{j}(s)
$$

Where $I(\cdot)$ is the indicator function, $C^{j}(s)$ is the number of patients in the risk set $\Omega_{j}(s)$, and $d N^{j}(s)$ is a dummy equal to one if any patient in hospital $j$ dies in an arbitrarily short period of time before duration $s$, and zero otherwise. The asymptotic covariance matrix of the vector $\hat{\Lambda}=\left[\hat{\Lambda}_{1}^{\prime}, \ldots \hat{\Lambda}_{J}^{\prime}\right]^{\prime}$ with $\hat{\Lambda}_{j}=\left[\hat{\Lambda}_{j}(1), \ldots, \hat{\Lambda}_{j}(T)\right]^{\prime}$, where $J$ is the number of hospitals and $T$ is the maximum number of days considered in the study, can be computed following Ridder and Tunali (1999), as shown in Appendix A.

The probability of death within duration $t$ after admission to hospital $j$ for a patient with the average effect of individual variables is given by:

$$
\bar{P}_{j}(t)=\exp \left[-\Lambda_{j}(t) \overline{\exp (X \beta)}\right]
$$

where $\overline{\exp (X \beta)}$ is the average of the effects of individual variables $\exp (X \beta)$, computed using the overall population of patients. ${ }^{7}$ An estimator of this probability of death is obtained by replacing $\beta$ and $\Lambda_{j}(t)$ with their estimators. In fact, we are rather interested in the probability of death within any given duration $t$ for an average patient admitted to a hospital with given status $k$, which can be for-profit, university or non-teaching. The theoretical expression for this probability of death is $\bar{P}^{k}(t)=E\left[\bar{P}_{j(i)}(t) \mid j(i) \in k\right]$, where the expectation is computed conditionally on being admitted to a hospital of status $k$. Consider the case where the average patient has probabilities of being admitted to hospitals that are simply given by the distribution of patients across hospitals. The empirical counterpart of the probability of death is then the average estimated probability of death computed across hospitals with the right status, weighted by the number of patients admitted to these hospitals:

$$
\hat{\bar{P}}^{k}(t)=\frac{1}{N^{k}} \sum_{j \in k} N_{j} \hat{\bar{P}}_{j}(t)
$$

where $N_{j}$ is the number of patients in hospital $j$ and $N^{k}$ is the number of patients in hospitals of

\footnotetext{
${ }^{7}$ Considering a patient with the average effect of individual characteristics is just a descriptive device for computing a probability of death whose level makes sense. Real counterfactuals are computed in Section VI.
} 
status k. The confidence interval of this estimated probability can be computed from its asymptotic variance, which can be obtained using the delta method. Indeed, $\hat{\bar{P}}^{k}(t)$ can be

expressed as a function of the vector $\left[\hat{\bar{P}}_{1}(t), \ldots, \hat{\bar{P}}_{J}(t)\right]^{\prime}$, which is itself a function of $\hat{\Lambda}$, whose asymptotic covariance matrices can be computed. ${ }^{8}$ An estimator of the standard error is obtained taking the square root of the asymptotic variance and is denoted $\hat{\sigma}^{k}(t)$. As the vector of integrated hazards of hospitals $\hat{\Lambda}$ is asymptotically normal, this is also true for the estimated probability of death in a hospital of status $k$, and the confidence interval of this estimated probability can be approximated with $\left[\hat{P}^{k}(t)-1.96 \hat{\sigma}^{k}(t), \hat{\bar{P}}^{k}(t)+1.96 \hat{\sigma}^{k}(t)\right]$. Alternatively, the confidence interval can also be bootstrapped.

We compare the probability of death across status when introducing different sets of patient variables (individual characteristics and/or treatment procedures). This approach allows us to compare the probabilities of death net of the effects of case-mix and innovative procedures between the three types of hospitals across durations.

\section{Construction of counterfactuals}

To quantify the disadvantage of non-teaching public hospitals in treating patients with innovative procedures compared to for-profit hospitals, we propose a counterfactual exercise. More precisely, we quantify the difference in probability of death for patients admitted to non-teaching public hospitals if they receive innovative treatment (catheter, possibly with angioplasty and stent) according to the assignment rule of for-profit hospitals rather than that of non-teaching public hospitals. Note that we do not compare the actual probability of death of patients in nonteaching public hospitals with the counterfactual probability of death derived from the treatment assignment rule of for-profit hospitals, as the selection of patients over time depends on their characteristics (due to transfers and home returns). This influences the actual probability of death. By contrast, the counterfactual probabilities of death obtained when assigning treatment

${ }^{8}$ In fact, $\overline{\exp (X \hat{\beta})}$ is an estimator with a sampling error which should be taken into account in the computation of the variance of $\hat{\bar{P}}^{k}(t)$. This is hard to do, and we therefore considered that the corresponding sampling error is negligible. This amounts to saying that $\overline{\exp (X \hat{\beta})}$ is simply a scaling factor used for normalizing the probability of death. 
alternatively with the rules of for-profit and non-teaching public hospitals are computed while holding the composition of patients constant across the days of stay.

More formally, the probability of death within $t$ days for patient $i$ with characteristics $X_{i}$ treated in a hospital $j(i)$ is given by:

$$
P\left(t \mid X_{i}\right)=1-\exp \left[-\Lambda_{j(i)}(t) \exp \left(X_{i} \beta\right)\right]
$$

We want to construct the average of this probability for patients admitted to non-teaching public hospitals if they were treated using the assignment rule of for-profit hospitals or non-teaching public hospitals, while holding the composition of patients constant across the days of stay. The counterfactual treatment will depend on patient characteristics. We divide the set of explanatory variables $X_{i}$ into a subset containing age-and-sex dummies, secondary diagnoses and comorbidity dummies, as well as the bypass dummy, denoted by $X_{i 1}$, and a dummy for catheter (possibly with angioplasty and stent), denoted by $X_{i 2}$.

The counterfactual probability of death for patients admitted to non-teaching public hospitals (whose type is denoted by $n t$ ) if they were treated using the assignment rule of a given hospital status $\ell$ (for-profit denoted $f p$ or non-teaching public $n t$ ) is given by:

$$
\tilde{P}^{\ell}(t)=\frac{1}{N^{n t}} \sum_{i \mid j(i) \in n t} E_{X_{i 2}^{\ell}}\left[P\left(t \mid X_{i}\right) \mid X_{i}=\left(X_{i 1}, X_{i 2}^{\ell}\right)\right]
$$

where $N^{n t}$ is the number of patients in non-teaching public hospitals, the sum is computed over all individuals whose hospital is of status $n t$, and $X_{i 2}^{\ell}$ the random variable corresponding to treatment when using the assignment rule of hospitals of type $\ell$. This assignment rule can depend on the first subset of explanatory variables $X_{i 1}$ considered to be exogenous. The probability of death can be rewritten as:

$$
\tilde{P}^{\ell}(t)=\frac{1}{N^{n t}} \sum_{i \mid j(i) \in n t} \sum_{k \in\{0,1\}} P\left(X_{i 2}^{\ell}=k \mid X_{i 1}\right) P\left(t \mid X_{i}=\left(X_{i 1}, k\right)\right)
$$

The right-hand side probabilities need to be evaluated. The probabilities $P\left(t \mid X_{i}=\left(X_{i 1}, k\right)\right)$ can be directly computed from their expression after replacing terms $\Lambda_{j}(t)$ and $\beta$ with their estimators. We model $P\left(X_{i 2}^{\ell}=1 \mid X_{i 1}\right)$ as a Probit whose parameters are estimated in the 
subsample of patients admitted to hospitals of type $\ell{ }^{9}$ These parameters are used to compute $P\left(X_{i 2}^{\ell}=k \mid X_{i 1}\right)$ for patients admitted to non-teaching public hospitals. The confidence intervals of the counterfactual average probabilities of death using alternatively the treatment assignment rules of for-profit and non-teaching public hospitals, as well as their differences, are computed using bootstrap.

\section{Estimation results}

Table 3 reports some of the estimated coefficients of patients' variables for three specifications (other coefficients, which are not of major interest, are reported in Table A.1. in Appendix). In column (1), only variables related to age, sex, comorbidities and secondary diagnoses are introduced. As usually reported in the literature, older people and women are more likely to die. The propensity to die is nearly constant across time. Comorbidities and secondary diagnoses have a negative or positive effect on in-hospital mortality. The negative effect is a little surprising, but patients with detected pathologies may be better monitored and thus better treated than other patients. Finally, the infarction site given by secondary diagnoses is an important determinant of the propensity to die.

In column (2), we add a dummy for catheter (possibly used jointly with an angioplasty or a stent). ${ }^{10}$ It has the expected negative effect on mortality. Finally, in column (3), we replace the dummy for catheter with dummies for detailed procedures (catheter only, angioplasty with catheter, stent with angioplasty and catheter). All the procedures have the expected negative effect on mortality. Note that the estimated coefficient of stent is lower in absolute terms than the estimated coefficient of catheter, whereas patients treated with a stent also have a catheter and their care is more costly for the hospital. In fact, surgeons treating patients use a catheter first and then add stents if they consider them necessary, because the patient is at risk from severely damaged arteries or veins. Nevertheless, we do not expect any sorting of patients across ownership status based on this risk, because this risk can be evaluated only when the surgical

\footnotetext{
${ }^{9}$ We implicitly assume that the dummy for by-pass surgery included in $X_{i 1}$ is exogenous. This makes sense, as bypass surgery usually has a specific use. Our assumption simplifies the analysis and is in fact innocuous, since the proportion of patients treated with bypass surgery is very small.

${ }^{10}$ We also added a dummy for by-pass surgery, but its introduction is innocuous for the analysis since only $0.9 \%$ of patients in our sample are treated with by-pass surgery. We could check that the introduction of this dummy does not affect our results.
} 
procedure to insert a catheter is performed.

\section{[ Insert Table 3 ]}

We now investigate the differences in probability of death between for-profit, university and nonteaching public hospitals when controlling for the different subsets of individual variables. ${ }^{11}$ Figure 2 represents the probability of death as a function of duration by type of hospital when controlling only for age, sex, comorbidities and secondary diagnoses in the first step (see also the values reported in Table 1). ${ }^{12}$ The probabilities of death in the different types of hospitals are much closer than those obtained on raw data (which are reported in Figure 1). ${ }^{13}$ During the first ten days, the period during which innovative procedures are performed, the probabilities of death in for-profit and university hospitals are lower than the probability of death in non-teaching public hospitals. University and for-profit hospitals have similar probabilities of death. After ten days, the probability of death in university hospitals is lower than that in for-profit hospitals. ${ }^{14}$

\section{[ Insert Figure 2 ]}

Figure 3 represents the probabilities of death obtained from the model when adding a dummy for catheter, possibly used jointly with an angioplasty or a stent (exact values are reported in Table 1). Non-teaching public hospitals now have the lowest mortality rates. It is possible to draw a comparison with clinical trials showing that aspirin, beta blockers and reperfusion explain the

\footnotetext{
${ }^{11}$ Estimated coefficients of dummies for hospital status included in a standard Cox model without stratification by hospital are reported in Table A.2. We conducted a Hausman test for the validity of the standard Cox model and it highly rejects the specification, whatever the set of explanatory variables introduced (see columns 1-3 of Table 3). For the full specification, including dummies for innovative treatments, the Hausman test statistic is 1580.1, whereas the threshold value for statistical significance at the 0.001 level is 59.7. Nevertheless, results obtained when using a standard Cox model are qualitatively in line with those obtained with the stratified Cox model, which are presented in the text.

${ }^{12}$ The level of probabilities cannot be directly compared between Figure 1 and Figures 2-4. Figure 1 represents the average probability of death by ownership status. By contrast, Figures 2-4 represent the probability of death for a patient with an average effect of individual variables by ownership status. Nevertheless, it is still insightful to compare the differences in probability of death between university, non-teaching public and for-profit hospitals across figures.

${ }^{13}$ Figure A.1 gives the probabilities of death with bootstrapped confidence intervals when using 100 replications rather than confidence intervals computed using their asymptotic distribution. Results are very close.

${ }^{14}$ Mortality in for-profit hospitals seems to catch up with that in non-teaching public hospitals after fourteen days. However, this result should be considered with caution, as changes in probabilities of death after ten days are computed with a limited number of patients (since most patients have been discharged), and selection biases may increase. In particular, after 14 days, only $14.5 \%$ of patients remain in our sample.
} 
substantial difference of 3.9 points in one-year survival between the highest and lowest quintiles of US hospitals ranked according to their rate of innovation diffusion across time (Skinner and Staiger, 2009). Here, catheters have an impact of 4.3 points on the mortality difference between for-profit and non-teaching public hospitals at 15 days, which is also large.

The change induced by the introduction of catheter can be explained by the more intensive use of catheters in university and for-profit hospitals and by the fact that the negative effect of catheters on mortality is now netted out. Interestingly, there is now a gap between for-profit and university hospitals even though their catheter use is similar. Differences in mortality rate across ownership status may be due to differences in healthcare organization. In particular, a for-profit hospital admitted on average 38 patients over the 1998-2003 period. The corresponding figure is nearly two times larger for a non-teaching public hospital, with an average of 72 patients, and around ten times larger for university hospitals, with an average of 362 patients.

\section{[ Insert Figure 3 ]}

Our results are confirmed by Figure 4, which represents the probabilities of death obtained when replacing the catheter with some dummies for detailed procedures (see also the values reported in

Table 1). ${ }^{15}$ We see that the curves remain unchanged. Overall, our results suggest that the quality of care in for-profit hospitals relies much on their capacity to perform innovative procedures. When neutralizing the effects of case-mix and innovative treatments on mortality, it is found that mortality is lower in public hospitals than in for-profit hospitals.

\section{[ Insert Figure 4 ]}

\footnotetext{
15 The results of the test using Schoenfeldt residuals suggest that the model is approximately a proportional hazard model. When considering alternatively every explanatory variable, the correlation between the Schoendeldt residual and time is always lower than 0.1 , and lower than 0.05 for all variables except two. However, the test most often rejects the nullity of correlation, and the overall test that all correlations are simultaneously zero is rejected at $1 \%$. The test result can be influenced by the large size of our sample though. When dropping the two patient characteristics with a correlation between 0.05 and 0.1 , the ranking between hospital statuses remains the same.
} 


\section{Endogeneity issues}

In this work, we study mortality using a competitive risk model where exits other than death -in particular home returns and transfers to another acute care hospital- are treated as censorship. A key assumption is that censorship is exogenous when conditional on patient variables and hospital effects. This assumption may be questioned because of selection on unobservables. Patients may be sent home because they are in good shape and thus exhibit unobserved characteristics that make them unlikely to die when back in their place of residence. Alternatively, some patients may be sent home because their health condition is very poor and they want to die in their bed. Moreover, transferred patients could be those in bad shape requiring the care of specialists that are located in other hospitals. Some establishments may also transfer very sick patients to avoid them dying on-site and negatively affect their statistics, and thus their reputation. As we are interested in mortality differences between hospital ownership statuses, selection on unobservables is an issue for us if we do not capture well the heterogeneity among patients, and if hospitals (according to their status) do not have the same practices for transfers and home returns.

The usual approach in the literature toward avoiding endogeneity issues is to control, as well as possible, patient comorbidities and secondary diagnoses that serve as proxies for health status. This is the approach adopted in our work. Most papers introduce only a comorbidity index on top of age and sex in regressions to control for heterogeneity in mortality risk among patients, as more detailed information is not available (see for instance Cooper et al., 2011). Here, we have some data at a fine level for comorbidities and secondary diagnoses. McClellan and Staiger (1999) show that, to take into account heterogeneity among patients, the main comorbidities and secondary diagnoses affecting mortality are enough, and more detailed medical data do not influence the results of the analyses. We believe that we are in line with published articles that have carefully taken into account heterogeneity among patients.

The existence of possible biases in the effect of catheter on mortality due to unobservables has also been raised by recent papers trying to construct bounds on the effect of catheter for different primary diagnoses. ${ }^{16}$ They find suggestive evidence that, for some primary diagnoses, the effect of catheter on survival may be underestimated (Bhattacharya, Shaikh and Vytlacil, 2012; Henry

\footnotetext{
${ }^{16}$ In particular, some methods make use of the weekday of admission as an instrument for treatment. We do not have such information in our data.
} 
and Mourifié, 2014). ${ }^{17}$ In our context, this means that, due to differences in innovative treatments, the difference in mortality between for-profit and non-teaching public hospitals may be even larger (although taking into account unobservables could also change the baseline hazards between the two types of hospitals). At the same time, our study includes many more secondary diagnoses and comorbidities than the papers cited, which study several primary diagnoses in a general way; and this lowers the likelihood of the biases they describe.

Despite our belief that unobserved characteristics are unlikely to play a large role, we also conduct a suggestive test of the existence of an endogeneity bias based on a sample that includes not only patients coming from home, but also those transferred from another acute care hospital. ${ }^{18}$ Indeed, transferred patients may not have the same characteristics as those coming from home, as they may be sent to the destination hospital for surgery because of a bad health condition or, alternatively, because their health condition is good enough that they can be moved to a more adequate establishment. Our test consists in introducing into our regressions a dummy for being transferred and assessing whether the related coefficient decreases in absolute terms towards zero as we introduce demographic, secondary diagnoses and comorbidity variables. Indeed, this would suggest that our patients' explanatory variables are likely to capture most of the individual heterogeneity.

Our complemented sample contains 397,303 stays, among which $18.0 \%$ are those of patients who have been transferred from another acute care hospital. Table 4 reports the estimated coefficients of patient variables for five specifications when varying the set of individual explanatory variables. In column 1, there are only year dummies and the dummy for being transferred from an acute care hospital. Patients being transferred are less likely to die than patients coming from home, with the estimated coefficient associated with the transfer dummy being -0.345 . Column 2 shows that when adding age-and-sex dummies, the transfer dummy decreases greatly in absolute terms and reaches -0.155 . This occurs because we now control for the fact that transferred patients are, on average, younger and thus less likely to die. Adding secondary diagnoses and comorbidities makes the coefficient decrease slightly more in absolute terms and it reaches -0.138 ,

\footnotetext{
${ }^{17}$ More precisely, they revisit the results obtained by Connors et al. (1996), who found for many primary diagnoses that catheter increases mortality. Using partial identification techniques based on the construction of bounds, they show that catheter would most often instead have a negative or non-significant effect on mortality.

${ }^{18}$ We thank the editor, Xavier D’Haultfoeuille, for suggesting this test.
} 
as shown in column 3; but this decrease is not statistically significant. The bottom line is that even important observable comorbidities do not much affect the estimated coefficient of the transfer dummy, and this estimated coefficient decreases in absolute term when adding patient characteristics and end up being rather small. In fact, the estimated effect of the transfer dummy is much smaller than age-and-sex effects, and also much smaller than most secondary diagnoses and comorbidity effects. The remaining negative effect can be due to unobserved comorbidities or to the decrease in mortality that is usually observed after a few days, as transferred patients have already spent some time in a hospital before their transfer. Interestingly, when adding a transfer dummy to specifications that include innovative treatments, the estimated coefficients of these treatments are only very marginally affected (see columns 4-8). This is also the case for mortality rates at 15 days for every ownership status which remains virtually unchanged. ${ }^{19}$ This suggests that innovative treatments and mortality rates for every ownership status are unlikely to reflect the effect of patient unobservables and, more generally, that patient unobservables play a lesser role.

[ Insert Table 4 ]

We also conducted an additional robustness check that consisted in conducting our analysis only for patients 80 years old and over. Indeed, we expect patients to be less strategic in their choice of hospital at that age, because they have less information on hospitals and perhaps less intellectual clarity. Results are qualitatively quite similar: the probability of death is more important in forprofit hospitals than in public hospitals once we have controlled for sex, comorbidities, secondary diagnoses and all innovative treatments. Indeed, the probability of death at 15 days is $27.6 \%$ in for-profit hospitals, but only $23.9 \%$ in university hospitals, and $24.0 \%$ in non-teaching hospitals. Interestingly, the mortality in university and non-teaching public hospitals is now very similar instead of being lower in non-teaching public hospitals, as in our benchmark results. This suggests a possible effect of patient unobserved heterogeneity on the relative ranking in the public sector. This is why we do not comment much on the net difference in mortality between non-teaching public and university hospitals in our paper, and prefer to stick to the net difference in mortality between for-profit and public hospitals.

\footnotetext{
${ }^{19}$ Corresponding figures are available upon request.
} 


\section{Implications of the results}

The important socio-economic question underlying our analysis is whether patients would receive better care in public hospitals -in particular, in non-teaching public hospitals- if these hospitals could treat them the same as for-profit hospitals.

Indeed, hospitals do not have the same incentives to treat patients with innovative procedures, as the reimbursement rules differ depending on the ownership status, and innovative procedures can be very costly. For instance, a stent for one stay induces an increase in costs that ranges from $30 \%$ to $60 \%$ (Dormont and Milcent, 2002). For-profit hospitals are financed via a fee-for-service system, and innovative supplies involving expensive devices that are used only once (e.g., angioplasty or stent) are reimbursed ex-post in addition to a fee-for-service payment. By contrast, non-teaching public hospitals have a limited global budget and all procedures, including the innovative ones, are charged to this budget. Hence, the use of expensive devices such as stents for a patient implies a lower budget for the care of other patients. It explains why the propensity to use innovative supplies is much lower in non-teaching public hospitals than in for-profit hospitals. Whereas teaching hospitals are also under the global budget system, they receive additional budget for their research activities. Part of this budget is used to purchase innovative devices, and therefore the propensity to treat patients with innovative procedures is higher than in non-teaching public hospitals. As shown in Table 2, this propensity is similar to that of for-profit hospitals.

To quantify the disadvantage of non-teaching public hospitals in treating patients as compared to for-profit hospitals, we conduct the counterfactual exercise presented in Section II. More precisely, we compare the counterfactual probabilities of death for patients admitted to nonteaching public hospitals, in particular when changing the treatment assignment rules from that of non-teaching public hospitals to that of for-profit hospitals. This is done by holding the composition of patients constant across the days of stay.

Table 5 shows that, for patients in non-teaching public hospitals, the average probability of death under the treatment assignment rule of non-teaching hospitals at 7 days is $7.56 \%{ }^{20}$ We then compute the average probability of death of the same patients under the treatment assignment rule of for-profit hospitals, and find it to be much lower at $5.73 \%$. Hence, the difference in

\footnotetext{
${ }^{20}$ Results of a Probit model for treatment with catheter (possibly with angioplasty and stent) by hospital status are reported in Table A.3.
} 
probability of death due in particular to a difference in treatments is rather large, reaching 1.83 points, and is highly significant.

\section{Conclusion}

Mortality differences between university, non-teaching public and for-profit hospitals are investigated using a French exhaustive administrative dataset on patients admitted for heart attack. The use of innovative procedures varies across ownership statuses, in particular because of different reimbursement rules. More specifically, whereas innovative procedures are reimbursed ex-post in addition to a fee-for-service payment to for-profit hospitals, there is a restrictive budget constraint for non-teaching public hospitals that significantly constrains their use of innovative procedures.

Our results show that innovative procedures are a key factor in explaining the high quality of care in for-profit hospitals. Moreover, when holding constant the use of innovative procedures and case-mix, the mortality rate in for-profit hospitals is higher than in public hospitals. When performing a counterfactual exercise, we also find that the probability of death at 7 days of patients admitted to non-teaching public hospitals would be 1.8 points lower if they were treated as in for-profit hospitals.

We have shown the important role of innovative procedures when studying hospital quality by ownership status over the 1998-2003 period. With the implementation of the French hospital payment reforms (T2A) in 2004-2008, financial incentives have changed for both public and forprofit hospitals. Public hospitals are not in a global budget system anymore, but are now paid a fee depending on the diagnosis-related group (DRG) of stays. For-profit hospitals have also adopted this system, although their fee by DRG is different (it can be higher or lower depending on the DRG). An interesting extension of our work could be to assess how these changes in the hospital payment system affect the quality of care by ownership status. 


\section{References}

Bhattacharya J., Shaikh A. and E. Vytlacil (2012), Treatment effect bounds: An application to SwanGanz catheterization, Journal of Econometrics, 168, pp. 223-243.

Bradley E., Herrin J., Mattera J., Holmboe E., Wang Y., et al. (2005), Quality Improvement Efforts and Hospital Performance: Rates of Beta-Blocker Prescription After Acute Myocardial Infarction, Medical Care, 43(3), pp. 282-92.

Breslow N.E. (1974), Covariance Analysis of Censored Survival Data, Biometrics, 30, pp. 89-99.

Connors A., Speroff T., Dawson N., Thomas C., Harrell F., Wagner D., Desbiens N., Goldman L., Wu A., Califf R., Fulkerson W., Vidaillet H., Broste S., Bellamy P., Lynn J. and W. Knaus (1996), The effectiveness of right heart catheterization in the initial care of critically ill patients. Journal of the American Medical Association, 276(11), pp 889-897.

Cooper Z., Gibbons S., Jones S. and A. McGuire (2011), Does Hospital Competition Save Lives? Evidence From The English NHS Patient Choice Reforms, The Economic Journal, 121(554), pp. F228-F260.

Cutler D. and M. McClellan (1996), The determinants of technological change in heart attack treatment, NBER Working Paper 5751.

Dormont, B., Milcent, C. (2002) Quelle régulation pour les hôpitaux publics français?, Revue d'Economie Politique, 17, pp. 117-142.

Gobillon L., Magnac T. and H. Selod (2011), The effect of location on finding a job in the Paris region, Journal of Applied Econometrics, 26(7), pp. 1079-1112.

Heidenreich, PA, and M. McClellan (2001), Trends in Treatment and Outcomes for Acute Myocardial Infarction: 1975-1995, The American Journal of Medicine, 110(3), pp. 165-174.

Henry M. and I. Mourifié (2014), Sharp Bounds in the Binary Roy Model, Working Paper 506, University of Toronto, Department of economics.

Ho V. (2002), Learning and the evolution of medical technologies: the diffusion of coronary angioplasty, Journal of Health Economics, 21, pp 873-885.

Horowitz J. (2008), Semiparametric and Nonparametric Methods in Econometrics, Springer Series in Statistics, 271p.

Kessler D. and M. McClellan (2001), The effects of hospital ownership on medical productivity, NBER Working Paper 8537.

Lawless J. (2003), Statistical Models and Methods for Lifetime Data, Wiley Series in Probability and Statistics, Second Edition, 630p.

Lien H., Chou S. and J. Liu (2008), Hospital ownership and performance: Evidence from stroke and 
cardiac treatment in Taiwan, Journal of Health Economics, 27, pp. 1208-1223.

McClellan M. and D. Staiger (1999), The Quality of Health Care Providers, NBER Working Paper 7327.

McClellan M. and D.O. Staiger (2000), Comparing Hospital Quality at For-Profit and Not-for-Profit Hospitals, pp. 93-112 in The Changing Hospital Industry: Comparing Not-for-Profit and For-Profit Institutions, D.M. Cutler ed., University of Chicago Press.

Ridder G. and I. Tunali (1999), Stratified partial likelihood estimation, Journal of Econometrics, 92(2), pp. 193-232.

Sloan F. (2000), Not-for-Profit Ownership and Hospital Behavior, in Handbook of Health Economics, vol. 1, ed. Culyer A.J. and J.P. Newhouse, Elsevier Science B.V., pp. 1141-1174.

Skinner J. and D. Staiger (2009), Technology Diffusion and Productivity Growth in Healthcare, NBER Working Paper 14865. 


\section{Appendix A:}

\section{Variance of estimated coefficients}

In this Appendix, we explain how to compute the covariance matrix of the hospital-specific integrated hazards following Ridder and Tunali (1999), the computations being summarized in Gobillon, Magnac and Selod (2011). We first introduce the following notations:

$$
\begin{aligned}
S_{j}^{0}(\beta, t) & =\sum_{i \in \Omega_{j(t)}} \exp \left(X_{i} \beta\right) \\
S_{j}^{1}(\beta, t) & =\sum_{i \in \Omega_{j(t)}} X_{i} \exp \left(X_{i} \beta\right)
\end{aligned}
$$

According to Ridder and Tunali (1999) - equation (A28), we have:

$$
\varepsilon_{j, t}=\eta_{j, t}+\frac{1}{\sqrt{N}} c_{j, t}^{\prime} \xi
$$

where $\varepsilon_{j, t}=\hat{\Lambda}_{j}(t)-\Lambda_{j}(t), N=\sum_{j} N_{j}$ and:

$$
\begin{aligned}
& \eta_{j, t}=\frac{1}{d_{j, t}} \int_{0}^{t} 1_{\left\{N_{j}(s)>0\right\}}\left[\frac{1}{S_{j}^{0}(\beta, s)} d N_{j}(s)-\lambda_{j}(s) d s\right] \\
& c_{j, t}=-\frac{1}{d_{j, t}} \int_{0}^{t} 1_{\left\{N_{j}(s)>0\right\}} \frac{S_{j}^{1}\left(\beta^{*}, s\right)}{\left[S_{j}^{0}\left(\beta^{*}, s\right)\right]^{2}} d N_{j}(s) \\
& \xi=\sqrt{ } N(\hat{\beta}-\beta)
\end{aligned}
$$

with $N_{j}(s)$ the number of patients still in hospital $j$ after duration $s, d_{j, t}=\int_{0}^{t} 1_{\left\{N_{j}(s)>0\right\}} d s$ the length of time before duration $t$ in which there is at least one patient at risk in hospital $j$, and $\beta^{*}$ a value between $\beta$ and $\hat{\beta}$ (which comes from a Taylor expansion not detailed here). The terms $\xi$ and $\eta_{j, t}$ are not correlated, and we obtain from equation (A1):

$$
\begin{aligned}
& V\left(\varepsilon_{j, t}\right)=V\left(\eta_{j, t}\right)+c_{j, t}^{\prime} V(\hat{\beta}) c_{j, t} \\
& \operatorname{cov}\left(\varepsilon_{j, t}, \varepsilon_{k, \tau}\right)=c_{j, t}^{\prime} V(\hat{\beta}) c_{k, \tau} \text { for } j \neq k \text { or } t \neq \tau
\end{aligned}
$$

The terms of the covariance matrix of $\left\{\varepsilon_{j, t}\right\}_{j, t}$ can be estimated using estimators of the right-hand side terms of these two equations. An estimator of $V(\hat{\beta})$ is obtained from the Fisher information matrix of the stratified partial likelihood estimation. It is not necessary to establish a theoretical 
formula for this estimator, as it can be directly recovered with the usual estimation software. Some estimators of $V\left(\eta_{j, t}\right)$ and $c_{j, t}$ are:

$$
\begin{gathered}
\hat{V}\left(\eta_{j, t}\right)=\frac{1}{\left(d_{j, t}\right)^{2}} \int_{0}^{t} 1_{\left\{N_{j}(s)>0\right\}} \frac{1}{\left[S_{j}^{0}(\hat{\beta}, s)\right]^{2}} d N_{j}(s) \\
\hat{c}_{j, t}=-\frac{1}{d_{j, t}} \int_{0}^{t} 1_{\left\{N_{j}(s)>0\right\}} \frac{S_{j}^{1}(\hat{\beta}, s)}{\left[S_{j}^{0}(\hat{\beta}, s)\right]^{2}} d N_{j}(s)
\end{gathered}
$$

These estimators have to be programmed in order to be computed. 
Table 1: Probability of death by model and ownership status

\begin{tabular}{|c|c|c|c|c|c|c|c|c|c|c|c|c|}
\hline & \multicolumn{3}{|c|}{ Non-parametric estimator } & \multicolumn{3}{|c|}{$\begin{array}{l}\text { Model including age, sex, diagnoses } \\
\text { and comorbidities }\end{array}$} & \multicolumn{3}{|c|}{$\begin{array}{l}\text { Model including age, sex, diagnoses, } \\
\text { comorbidities and catheter }\end{array}$} & \multicolumn{3}{|c|}{$\begin{array}{l}\text { Model including age, sex, diagnoses, } \\
\text { comorbidities and procedures }\end{array}$} \\
\hline & For-profit & University & Non-teaching & For-profit & University & Non-teaching & For-profit & University & Non-teaching & For-profit & University & Non-teaching \\
\hline 1 day & $\begin{array}{c}0.012 \\
{[0.012,0.013]}\end{array}$ & $\begin{array}{c}0.014 \\
{[0.013,0.015]}\end{array}$ & $\begin{array}{c}0.023 \\
{[0.022,0.024]}\end{array}$ & $\begin{array}{c}0.015 \\
{[0.014,0.016]}\end{array}$ & $\begin{array}{c}0.016 \\
{[0.015,0.017]}\end{array}$ & $\begin{array}{c}0.020 \\
{[0.019,0.021]}\end{array}$ & $\begin{array}{c}0.020 \\
{[0.018,0.021]}\end{array}$ & $\begin{array}{c}0.018 \\
{[0.017,0.019]}\end{array}$ & $\begin{array}{c}0.019 \\
{[0.018,0.019]}\end{array}$ & $\begin{array}{c}0.020 \\
{[0.018,0.021]}\end{array}$ & $\begin{array}{c}0.018 \\
{[0.017,0.019]}\end{array}$ & $\begin{array}{c}0.019 \\
{[0.018,0.019]}\end{array}$ \\
\hline 3 days & $\begin{array}{c}0.029 \\
{[0.028,0.030]}\end{array}$ & $\begin{array}{c}0.030 \\
{[0.029,0.031]}\end{array}$ & $\begin{array}{c}0.048 \\
{[0.047,0.049]}\end{array}$ & $\begin{array}{c}0.034 \\
{[0.032,0.036]}\end{array}$ & $\begin{array}{c}0.034 \\
{[0.033,0.036]}\end{array}$ & $\begin{array}{c}0.042 \\
{[0.041,0.043]}\end{array}$ & $\begin{array}{c}0.046 \\
{[0.043,0.048]}\end{array}$ & $\begin{array}{c}0.041 \\
{[0.039,0.042]}\end{array}$ & $\begin{array}{c}0.039 \\
{[0.038,0.041]}\end{array}$ & $\begin{array}{c}0.045 \\
{[0.043,0.048]}\end{array}$ & $\begin{array}{c}0.040 \\
{[0.038,0.042]}\end{array}$ & $\begin{array}{c}0.039 \\
{[0.038,0.041]}\end{array}$ \\
\hline 5 days & $\begin{array}{c}0.042 \\
{[0.041,0.044]}\end{array}$ & $\begin{array}{c}0.044 \\
{[0.042,0.045]}\end{array}$ & $\begin{array}{c}0.066 \\
{[0.065,0.068]}\end{array}$ & $\begin{array}{c}0.049 \\
{[0.047,0.051]}\end{array}$ & $\begin{array}{c}0.049 \\
{[0.047,0.051]}\end{array}$ & $\begin{array}{c}0.057 \\
{[0.056,0.059]}\end{array}$ & $\begin{array}{c}0.066 \\
{[0.063,0.069]}\end{array}$ & $\begin{array}{c}0.058 \\
{[0.056,0.060]}\end{array}$ & $\begin{array}{c}0.054 \\
{[0.052,0.055]}\end{array}$ & $\begin{array}{c}0.065 \\
{[0.062,0.068]}\end{array}$ & $\begin{array}{c}0.057 \\
{[0.055,0.059]}\end{array}$ & $\begin{array}{c}0.054 \\
{[0.052,0.056]}\end{array}$ \\
\hline 10 days & $\begin{array}{c}0.074 \\
{[0.071,0.077]}\end{array}$ & $\begin{array}{c}0.071 \\
{[0.068,0.073]}\end{array}$ & $\begin{array}{c}0.104 \\
{[0.102,0.106]}\end{array}$ & $\begin{array}{c}0.079 \\
{[0.075,0.083]}\end{array}$ & $\begin{array}{c}0.075 \\
{[0.072,0.078]}\end{array}$ & $\begin{array}{c}0.085 \\
{[0.083,0.087]}\end{array}$ & $\begin{array}{c}0.107 \\
{[0.102,0.112]}\end{array}$ & $\begin{array}{c}0.088 \\
{[0.085,0.091]}\end{array}$ & $\begin{array}{c}0.080 \\
{[0.078,0.082]}\end{array}$ & $\begin{array}{c}0.106 \\
{[0.101,0.0111]}\end{array}$ & $\begin{array}{c}0.087 \\
{[0.084,0.090]}\end{array}$ & $\begin{array}{c}0.080 \\
{[0.078,0.083]}\end{array}$ \\
\hline 15 days & $\begin{array}{c}0.113 \\
{[0.107,0.120]}\end{array}$ & $\begin{array}{c}0.104 \\
{[0.101,0.108]}\end{array}$ & $\begin{array}{c}0.145 \\
{[0.142,0.148]}\end{array}$ & $\begin{array}{c}0.110 \\
{[0.104,0.117]}\end{array}$ & $\begin{array}{c}0.100 \\
{[0.097,0.104]}\end{array}$ & $\begin{array}{c}0.110 \\
{[0.107,0.113]}\end{array}$ & $\begin{array}{c}0.149 \\
{[0.140,0.158]}\end{array}$ & $\begin{array}{c}0.117 \\
{[0.113,0.121]}\end{array}$ & $\begin{array}{c}0.104 \\
{[0.101,0.108]}\end{array}$ & $\begin{array}{c}0.147 \\
{[0.139,0.156]}\end{array}$ & $\begin{array}{c}0.116 \\
{[0.111,0.120]}\end{array}$ & $\begin{array}{c}0.105 \\
{[0.102,0.108]}\end{array}$ \\
\hline
\end{tabular}

Note: For a given duration, the point estimate is reported on the first row and the confidence interval is reported in brackets on the second row. Details on the computation of the non-parametric estimator of the probability of death is given in Section II, and details on the computation of the estimator of the probability of death derived from the model are given in Section III. 
Table 2: descriptive statistics

\begin{tabular}{|c|c|c|c|c|}
\hline & For-profit & University & Non-teaching & All \\
\hline Death & 0.060 & 0.064 & 0.097 & 0.080 \\
\hline Home & 0.699 & 0.697 & 0.481 & 0.588 \\
\hline Transfer to another service ${ }^{a}$ & 0.005 & 0.013 & 0.029 & 0.019 \\
\hline Transfer to another acute care hospital & 0.149 & 0.140 & 0.335 & 0.241 \\
\hline Transfer to another type of hospital & 0.087 & 0.086 & 0.058 & 0.072 \\
\hline Duration, death & 6.621 & 7.445 & 6.577 & 6.783 \\
\hline Duration, home & 7.381 & 7.738 & 9.519 & 8.386 \\
\hline Duration, transfer to another acute care hospital & 6.480 & 6.976 & 6.081 & 6.280 \\
\hline Duration, transfer to another service & 11.308 & 14.910 & 16.645 & 16.018 \\
\hline Duration, transfer to another type of hospital & 9.600 & 12.624 & 13.231 & 12.112 \\
\hline \multicolumn{5}{|l|}{ Demographic characteristics } \\
\hline Female, age $35-60$ & 0.035 & 0.041 & 0.031 & 0.035 \\
\hline Female, age $60-70$ & 0.046 & 0.045 & 0.043 & 0.044 \\
\hline Female, age $70-80$ & 0.100 & 0.088 & 0.108 & 0.101 \\
\hline Female, age $81+$ & 0.102 & 0.106 & 0.171 & 0.138 \\
\hline Male, age $35-60$ & 0.268 & 0.311 & 0.219 & 0.256 \\
\hline Male, age $60-70$ & 0.174 & 0.169 & 0.141 & 0.156 \\
\hline Male, age $70-80$ & 0.189 & 0.162 & 0.175 & 0.174 \\
\hline Male, age $81+$ & 0.087 & 0.076 & 0.111 & 0.096 \\
\hline \multicolumn{5}{|l|}{ Secondary diagnoses and comorbidities } \\
\hline Alcohol problems & 0.011 & 0.009 & 0.013 & 0.012 \\
\hline Diabetes & 0.169 & 0.144 & 0.152 & 0.153 \\
\hline Obesity & 0.082 & 0.065 & 0.052 & 0.062 \\
\hline Renal failure & 0.046 & 0.046 & 0.052 & 0.049 \\
\hline Excessive smoking & 0.144 & 0.143 & 0.098 & 0.120 \\
\hline Hypertension & 0.356 & 0.277 & 0.284 & 0.297 \\
\hline Vascular disease & 0.068 & 0.030 & 0.040 & 0.043 \\
\hline Peripheral arterial disease & 0.076 & 0.052 & 0.060 & 0.061 \\
\hline Stroke & 0.033 & 0.025 & 0.033 & 0.031 \\
\hline History of coronary artery disease & 0.058 & 0.030 & 0.037 & 0.039 \\
\hline Heart failure & 0.130 & 0.129 & 0.183 & 0.156 \\
\hline Conduction disease & 0.203 & 0.156 & 0.214 & 0.195 \\
\hline Location unknown or not reported & 0.321 & 0.253 & 0.283 & 0.282 \\
\hline Anterior location & 0.325 & 0.269 & 0.278 & 0.285 \\
\hline Posterior location & 0.113 & 0.092 & 0.117 & 0.109 \\
\hline Sub-endocardial & 0.103 & 0.064 & 0.088 & 0.085 \\
\hline Other location & 0.138 & 0.322 & 0.233 & 0.239 \\
\hline \multicolumn{5}{|l|}{ Treatments } \\
\hline CABG or Coronary Bypass surgery & 0.015 & 0.020 & 0.000 & 0.009 \\
\hline Catheter (possibly with angioplasty/stent) & 0.704 & 0.698 & 0.278 & 0.487 \\
\hline Catheter alone & 0.238 & 0.231 & 0.146 & 0.190 \\
\hline Catheter with dilatation & 0.061 & 0.112 & 0.022 & 0.056 \\
\hline Catheter with dilatation and stent & 0.405 & 0.355 & 0.109 & 0.241 \\
\hline
\end{tabular}

Note: a " "Another service" refers to a service which is not ischemic, where patients are treated for a pathology different from their AMI. "Duration, $X$ ” gives the average duration of stay for patients experiencing an exit of type X. 
Table 3: Cox model stratified by hospital, propensity to die

\begin{tabular}{|c|c|c|c|}
\hline Explanatory variables & $\begin{array}{l}\text { Age, sex, } \\
\text { diagnoses }\end{array}$ & $\begin{array}{c}\text { Age, sex, } \\
\text { diagnoses, } \\
\text { catheter }\end{array}$ & $\begin{array}{c}\text { Age, sex, } \\
\text { diagnoses, and all } \\
\text { procedures }\end{array}$ \\
\hline Female, age $35-60$ & $<$ ref $>$ & $<$ ref $>$ & $<$ ref $>$ \\
\hline Female, age $60-70$ & $\begin{array}{c}0.659 * * * \\
(0.081)\end{array}$ & $\begin{array}{c}0.592^{* * *} \\
(0.081)\end{array}$ & $\begin{array}{l}0.594^{* * *} \\
(0.081)\end{array}$ \\
\hline Female, age $70-80$ & $\begin{array}{c}1.182^{* * *} \\
(0.073)\end{array}$ & $\begin{array}{c}1.007^{* * *} \\
(0.073)\end{array}$ & $\begin{array}{c}1.008 * * * \\
(0.073)\end{array}$ \\
\hline Female, age $81+$ & $\begin{array}{c}1.821^{* * *} \\
(0.071)\end{array}$ & $\begin{array}{c}1.447^{* * *} \\
(0.072)\end{array}$ & $\begin{array}{c}1.447^{* * *} \\
(0.072)\end{array}$ \\
\hline Male, age $35-60$ & $\begin{array}{c}-0.459 * * * \\
(0.078)\end{array}$ & $\begin{array}{c}-0.433^{* * *} \\
(0.078)\end{array}$ & $\begin{array}{c}-0.444 * * * \\
(0.078)\end{array}$ \\
\hline Male, age $60-70$ & $\begin{array}{c}0.380 * * * \\
(0.075)\end{array}$ & $\begin{array}{c}0.350 * * * \\
(0.075)\end{array}$ & $\begin{array}{c}0.347^{* * *} \\
(0.075)\end{array}$ \\
\hline Male, age $70-80$ & $\begin{array}{c}1.009 * * * \\
(0.072)\end{array}$ & $\begin{array}{c}0.882^{* * *} \\
(0.072)\end{array}$ & $\begin{array}{c}0.883 * * * \\
(0.072)\end{array}$ \\
\hline Male, age $81+$ & $\begin{array}{c}1.652^{* * *} \\
(0.072)\end{array}$ & $\begin{array}{c}1.321^{* * *} \\
(0.072)\end{array}$ & $\begin{array}{l}1.321 * * * \\
(0.072)\end{array}$ \\
\hline CABG or Coronary Bypass surgery & & $\begin{array}{c}-0.663^{* * *} \\
(0.084)\end{array}$ & $\begin{array}{c}-0.614^{* * *} \\
(0.084)\end{array}$ \\
\hline $\begin{array}{l}\text { Catheter } \\
\text { (possibly with dilatation or stent) }\end{array}$ & & $\begin{array}{c}-1.074 * * * \\
(0.021)\end{array}$ & $\begin{array}{c}-0.900 * * * \\
(0.091)\end{array}$ \\
\hline Catheter alone & & & $\begin{array}{c}-1.289 * * * \\
(0.031)\end{array}$ \\
\hline Catheter with dilatation & & & $\begin{array}{c}-0.667^{* * *} \\
(0.040)\end{array}$ \\
\hline Catheter with dilatation and stent & & & $\begin{array}{c}-1.030 * * * \\
(0.028)\end{array}$ \\
\hline Year Dummies & $x$ & $x$ & $x$ \\
\hline $\begin{array}{l}\text { Dummies for comorbidities and } \\
\text { secondary diagnoses }\end{array}$ & $x$ & $x$ & $x$ \\
\hline Number of observations & 325,760 & 325,760 & 325,760 \\
\hline Number of deaths & 25,964 & 25,964 & 25,964 \\
\hline
\end{tabular}

Note: ***: significant at 1\% level; **: significant at 5\% level; *: significant at $10 \%$ level. Dummies for year of admission, comorbidities and secondary diagnoses are included, and their estimated coefficients are reported in Table A.1. 
Table 4: Cox model stratified by hospital, propensity to die

The sample includes patients transferred from another acute care hospital

A dummy for being transferred is included in the regressions

\begin{tabular}{|c|c|c|c|c|c|c|c|}
\hline Explanatory variables & None & Age, sex & $\begin{array}{l}\text { Age, sex, } \\
\text { diagnoses }\end{array}$ & $\begin{array}{l}\text { Age, sex, } \\
\text { diagnoses, } \\
\text { catheter }\end{array}$ & $\begin{array}{l}\text { Age, sex, } \\
\text { diagnoses, } \\
\text { and all } \\
\text { procedures }\end{array}$ & $\begin{array}{l}\text { Age, sex, } \\
\text { diagnoses, } \\
\text { catheter }\end{array}$ & $\begin{array}{l}\text { Age, sex, } \\
\text { diagnoses, } \\
\text { and all } \\
\text { procedures }\end{array}$ \\
\hline Catheter & & & & $-1.010 * * *$ & & $-1.012^{* * *}$ & \\
\hline (possibly with dilatation or stent) & & & & $(0.020)$ & & $(0.020)$ & \\
\hline Catheter alone & & & & & $\begin{array}{c}-1.176^{* * *} \\
(0.028)\end{array}$ & & $\begin{array}{c}-1.178 * * * \\
(0.028)\end{array}$ \\
\hline Catheter with dilatation & & & & & $\begin{array}{c}-0.640 * * * \\
(0.037)\end{array}$ & & $\begin{array}{c}-0.642 * * * \\
(0.037)\end{array}$ \\
\hline Catheter with dilatation and stent & & & & & $\begin{array}{c}-0.990^{* * *} \\
(0.025)\end{array}$ & & $\begin{array}{c}-0.991 * * * \\
(0.025)\end{array}$ \\
\hline Transferred & $\begin{array}{c}-0.345^{* * *} \\
(0.022)\end{array}$ & $\begin{array}{c}-0.155^{* * *} \\
(0.022) \\
\end{array}$ & $\begin{array}{c}-0.138 * * * \\
(0.022)\end{array}$ & $\begin{array}{c}-0.113^{* * *} \\
(0.022) \\
\end{array}$ & $\begin{array}{c}-0.114^{* * *} \\
(0.022)\end{array}$ & & \\
\hline Year dummies & $\mathrm{x}$ & $x$ & $\mathrm{x}$ & $\mathrm{x}$ & $x$ & $x$ & $x$ \\
\hline $\begin{array}{l}\text { Age-and-sex dummies } \\
\text { Dummies for secondary diagnoses } \\
\text { and comorbidities }\end{array}$ & & $x$ & $\begin{array}{l}x \\
X\end{array}$ & $\begin{array}{l}X \\
x\end{array}$ & $\begin{array}{l}x \\
x\end{array}$ & $\begin{array}{l}x \\
x\end{array}$ & $\begin{array}{l}x \\
x\end{array}$ \\
\hline Number of observations & 397,303 & 397,303 & 397,303 & 397,303 & 397,303 & 397,303 & 397,303 \\
\hline Number of deaths & 28,622 & 28,622 & 28,622 & 28,622 & 28,622 & 28,622 & 28,622 \\
\hline
\end{tabular}

Note: ***: significant at $1 \%$ level; **: significant at $5 \%$ level; *: significant at $10 \%$ level. 
Table 5: Counterfactual probability of death (in \%) as a function of duration (in days) for patients admitted to non-teaching public hospitals

\begin{tabular}{|c|c|c|c|}
\hline Duration & Non-teaching & For-profit & Difference \\
\hline \multirow[t]{2}{*}{1} & 2,25 & 1,70 & $-0,55$ \\
\hline & {$[2,19 ; 2,31]$} & {$[1,65 ; 1,75]$} & {$[-0,57 ;-0,53]$} \\
\hline \multirow[t]{2}{*}{2} & 3,65 & 2,76 & $-0,89$ \\
\hline & {$[3,57 ; 3,72]$} & {$[2,70 ; 2,81]$} & {$[-0,92 ;-0,86]$} \\
\hline \multirow[t]{2}{*}{3} & 4,67 & 3,53 & $-1,14$ \\
\hline & {$[4,57 ; 4,75]$} & {$[3,46 ; 3,60]$} & {$[-1,17 ;-1,11]$} \\
\hline \multirow[t]{2}{*}{4} & 5,57 & 4,22 & $-1,35$ \\
\hline & {$[5,47 ; 5,66]$} & {$[4,14 ; 4,29]$} & {$[-1,39 ;-1,32]$} \\
\hline \multirow[t]{2}{*}{5} & 6,32 & 4,78 & $-1,53$ \\
\hline & {$[6,22 ; 6,41]$} & {$[4,70 ; 4,88]$} & {$[-1,58 ;-1,49]$} \\
\hline \multirow[t]{2}{*}{6} & 6,97 & 5,28 & $-1,69$ \\
\hline & {$[6,85 ; 7,07]$} & {$[5,19 ; 5,37]$} & {$[-1,73 ;-1,64]$} \\
\hline \multirow[t]{2}{*}{7} & 7,56 & 5,73 & $-1,83$ \\
\hline & {$[7,45 ; 7,67]$} & {$[5,65 ; 5,84]$} & {$[-1,88 ;-1,78]$} \\
\hline \multirow[t]{2}{*}{8} & 8,10 & 6,14 & $-1,96$ \\
\hline & {$[8,00 ; 8,21]$} & {$[6,06 ; 6,24]$} & {$[-2,01 ;-1,91]$} \\
\hline \multirow[t]{2}{*}{9} & 8,65 & 6,57 & $-2,09$ \\
\hline & {$[8,54 ; 8,77]$} & {$[6,47 ; 6,67]$} & {$[-2,14 ;-2,03]$} \\
\hline \multirow[t]{2}{*}{10} & 9,18 & 6,96 & $-2,21$ \\
\hline & {$[9,05 ; 9,31]$} & {$[6,85 ; 7,07]$} & {$[-2,26 ;-2,15]$} \\
\hline \multirow[t]{2}{*}{11} & 9,70 & 7,36 & $-2,33$ \\
\hline & {$[9,57 ; 9,83]$} & {$[7,25 ; 7,47]$} & {$[-2,39 ;-2,27]$} \\
\hline \multirow[t]{2}{*}{12} & 10,23 & 7,77 & $-2,46$ \\
\hline & {$[10,10 ; 10,40]$} & {$[7,66 ; 7,88]$} & {$[-2,52 ;-2,39]$} \\
\hline \multirow[t]{2}{*}{13} & 10,71 & 8,14 & $-2,57$ \\
\hline & {$[10,55 ; 10,88]$} & {$[8,01 ; 8,26]$} & {$[-2,63 ;-2,50]$} \\
\hline \multirow[t]{2}{*}{14} & 11,20 & 8,52 & $-2,68$ \\
\hline & {$[11,03 ; 11,37]$} & {$[8,36 ; 8,67]$} & {$[-2,75 ;-2,61]$} \\
\hline \multirow[t]{2}{*}{15} & 11,72 & 8,91 & $-2,80$ \\
\hline & {$[11,55 ; 11,91]$} & {$[8,76 ; 9,07]$} & {$[-2,87 ;-2,72]$} \\
\hline
\end{tabular}

Note: the counterfactual probability of death after a duration given in column 1 is computed considering that the treatments of patients admitted to non-teaching public hospitals are allocated following the assignment rule of either non-teaching public hospitals themselves (column 2) or for-profit hospitals (column 3). Confidence intervals are in brackets under coefficients, and are bootstrapped using 100 replications. 
Figure 1: Probability of death as a function of duration (in days), non-parametric estimator

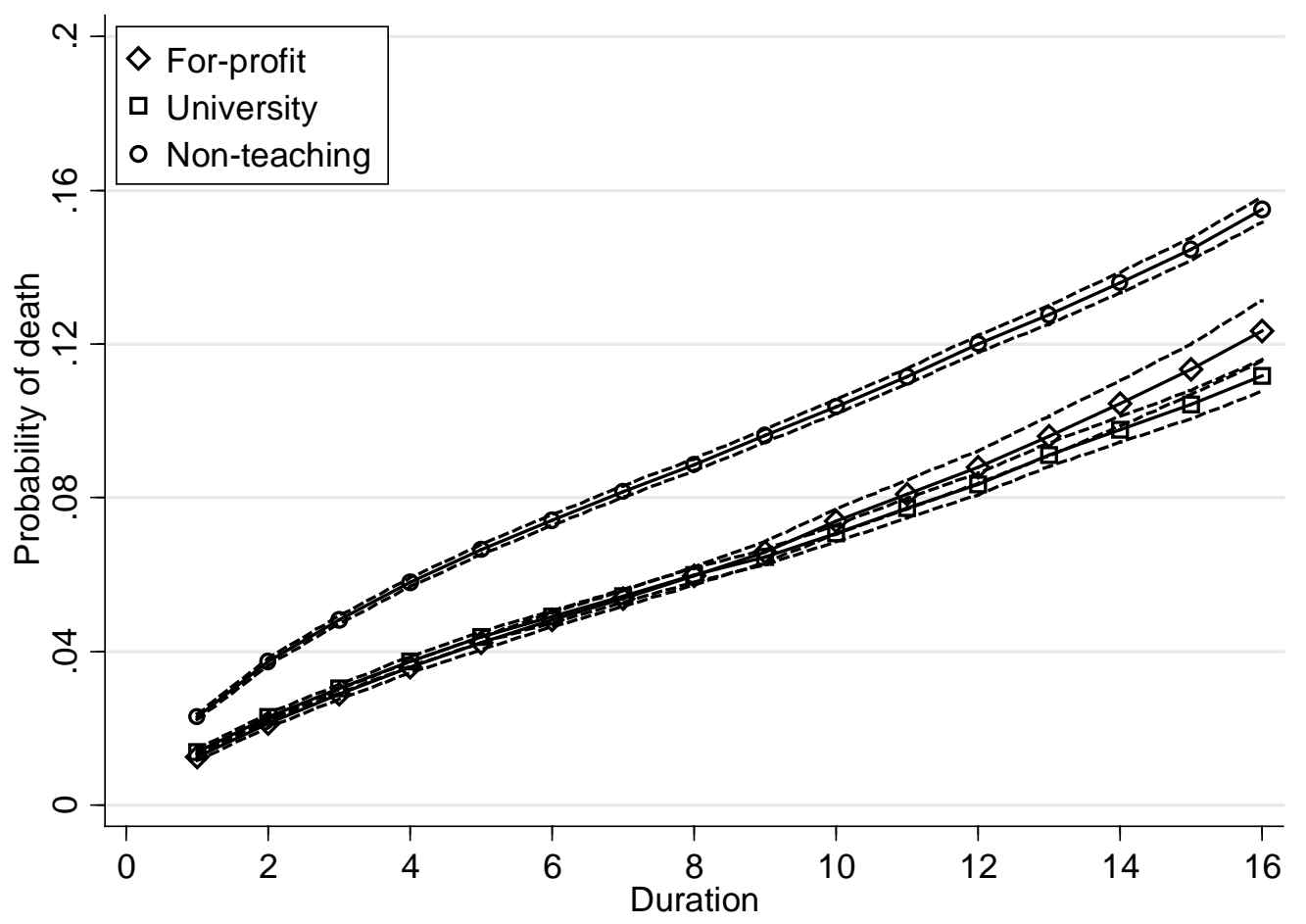

Note: for a given hospital status, an aggregate survival function is computed as a weighted average of the Kaplan-Meier estimators of survival functions for hospitals with that status, where the weight is the number of patients admitted to each hospital. The probability of death is then defined as one minus the resulting aggregate survival function. The probability of death at $t$ days is thus the probability that the patient has died within the first $t$ days. 
Figure 2: Probability of death as a function of duration (in days), from a model including age $x$ sex, secondary diagnoses and comorbidities

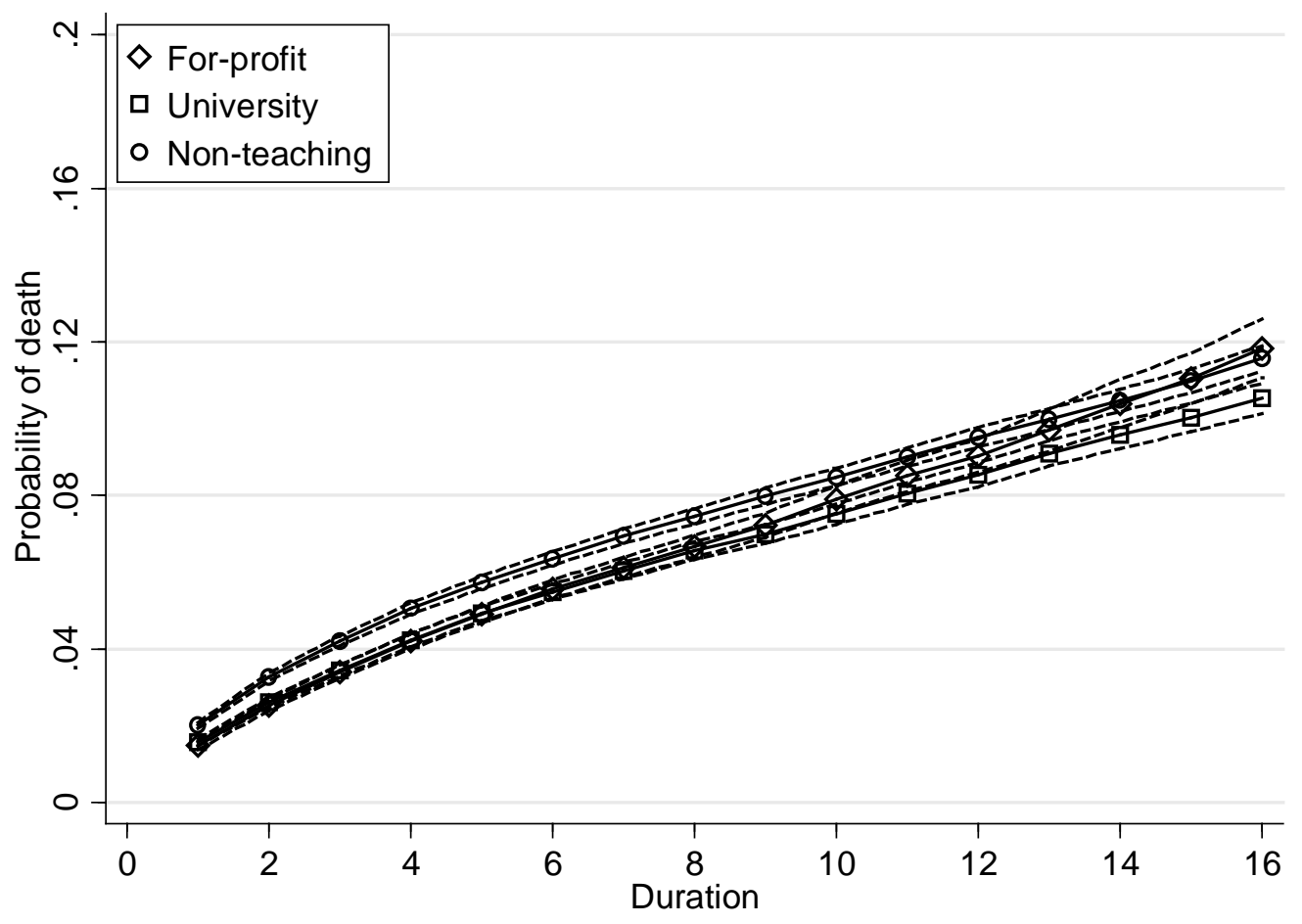

Note: for a given hospital status, an aggregate probability of death is computed as a weighted average of the estimated probabilities of death for hospitals with that status (each probability of death being obtained as the exponential of minus the Breslow estimator of the integrated hazard for a patient with the average effect of individual variables), where the weight is the number of patients admitted to each hospital. The probability of death at $t$ days is thus the probability that the patient has died within the first t days. 
Figure 3: Probability of death as a function of duration (in days), from a model including age $\mathrm{x}$ sex, secondary diagnoses, comorbidities and catheter

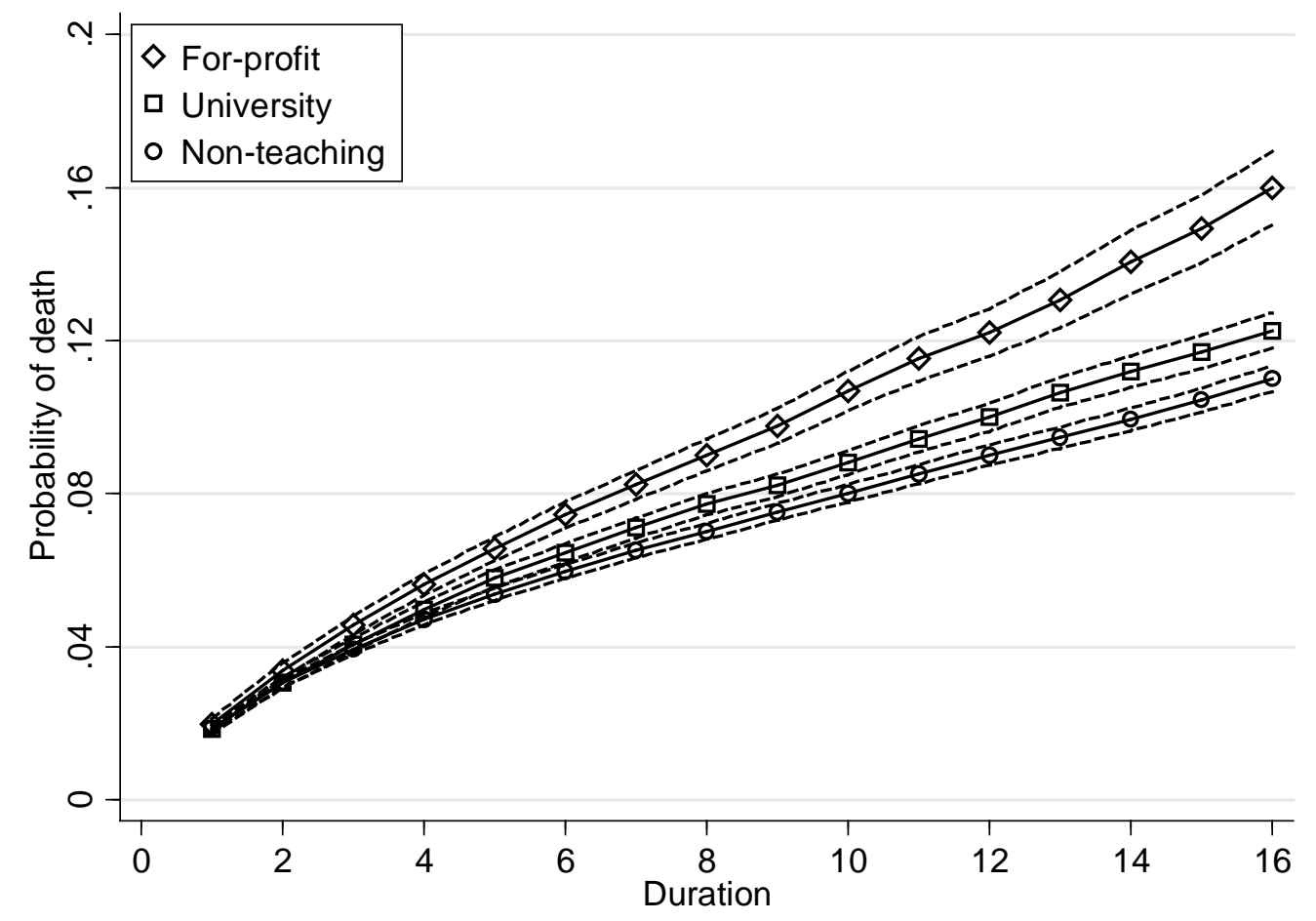

Note: for a given hospital status, an aggregate probability of death is computed as a weighted average of the estimated probabilities of death for hospitals with that status (each probability of death being obtained as the exponential of minus the Breslow estimator of the integrated hazard for a patient with the average effect of individual variables), where the weight is the number of patients admitted to each hospital. The probability of death at $t$ days is thus the probability that the patient has died within the first t days. 
Figure 4: Probability of death as a function of duration (in days), from a model including age x sex, secondary diagnoses, comorbidities and procedures

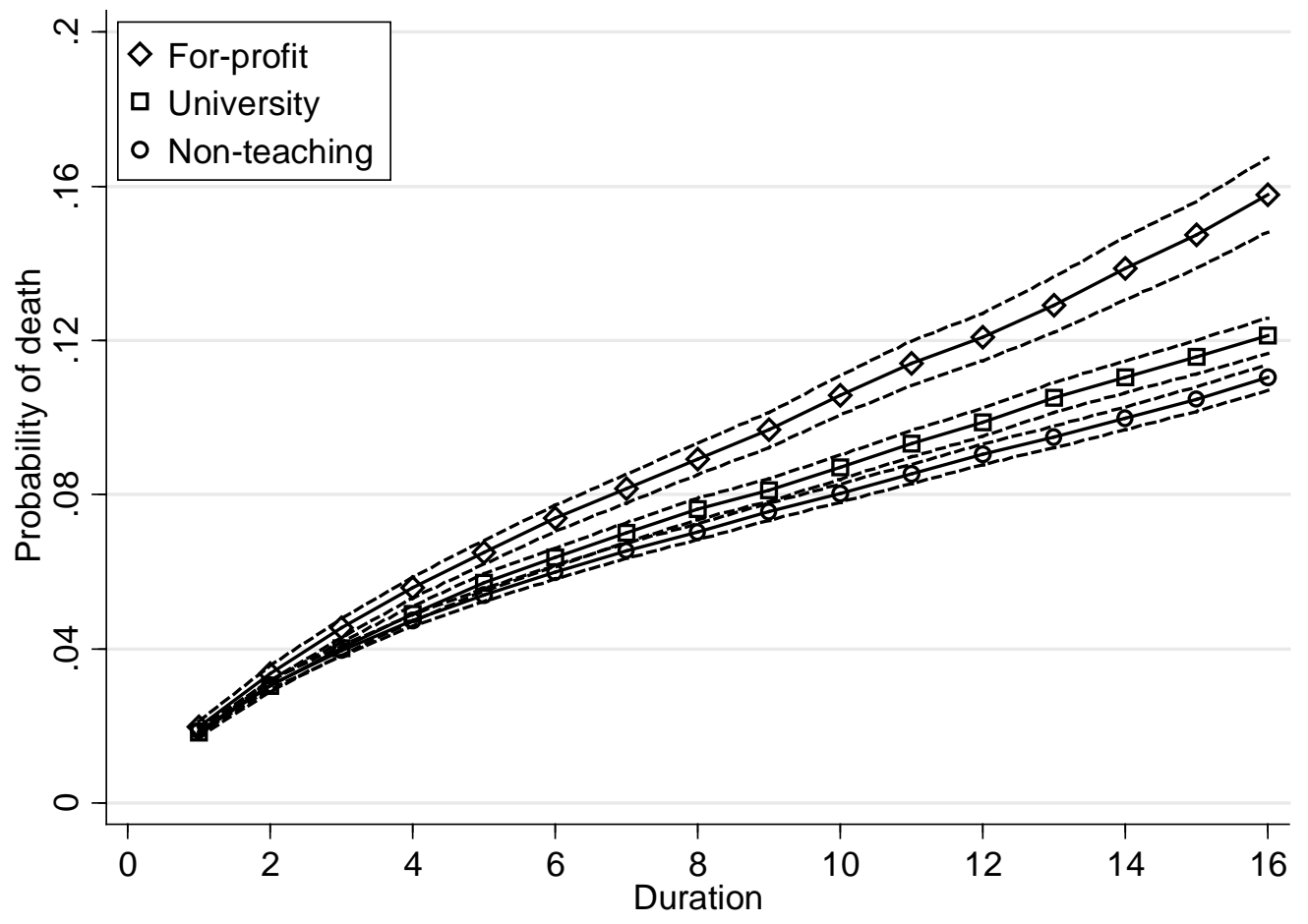

Note: for a given hospital status, an aggregate probability of death is computed as a weighted average of the estimated probabilities of death for hospitals with that status (each probability of death being obtained as the exponential of minus the Breslow estimator of the integrated hazard for a patient with the average effect of individual variables), where the weight is the number of patients admitted to each hospital. The probability of death at $\mathrm{t}$ days is thus the probability that the patient has died within the first t days. 
Table A.1: Cox model stratified by hospital, propensity to die

Estimated coefficients for dummies for year of admission, comorbidities and secondary diagnoses

\begin{tabular}{|c|c|c|c|}
\hline Explanatory variables & $\begin{array}{l}\text { Age, sex, } \\
\text { diagnoses }\end{array}$ & $\begin{array}{c}\text { Age, sex, } \\
\text { diagnoses, } \\
\text { catheter }\end{array}$ & $\begin{array}{c}\text { Age, sex, } \\
\text { diagnoses, and all } \\
\text { procedures }\end{array}$ \\
\hline Year 1998 & $<$ ref $>$ & $<$ ref $>$ & $<$ ref $>$ \\
\hline \multirow[t]{2}{*}{ Year 1999} & 0.032 & $0.047 * *$ & $0.047 * *$ \\
\hline & $(0.022)$ & $(0.022)$ & $(0.022)$ \\
\hline \multirow[t]{2}{*}{ Year 2000} & -0.004 & 0.033 & 0.035 \\
\hline & $(0.022)$ & $(0.022)$ & $(0.022)$ \\
\hline \multirow[t]{2}{*}{ Year 2001} & -0.001 & $0.056^{* *}$ & $0.057 * *$ \\
\hline & $(0.022)$ & $(0.022)$ & $(0.022)$ \\
\hline \multirow[t]{2}{*}{ Year 2002} & -0.026 & 0.031 & 0.031 \\
\hline & $(0.022)$ & $(0.022)$ & $(0.022)$ \\
\hline \multirow[t]{2}{*}{ Year 2003} & -0.031 & 0.025 & 0.025 \\
\hline & $(0.023)$ & $(0.023)$ & $(0.023)$ \\
\hline \multirow[t]{2}{*}{ Alcohol problems } & $0.450 * * *$ & $0.345 * * *$ & $0.346 * * *$ \\
\hline & $(0.066)$ & $(0.066)$ & $(0.066)$ \\
\hline \multirow[t]{2}{*}{ Diabetes } & $-0.048 * * *$ & $-0.061 * * *$ & $-0.061 * * *$ \\
\hline & $(0.018)$ & $(0.018)$ & $(0.018)$ \\
\hline \multirow[t]{2}{*}{ Obesity } & $-0.286 * * *$ & $-0.232 * * *$ & $-0.233 * * *$ \\
\hline & $(0.042)$ & $(0.042)$ & $(0.042)$ \\
\hline \multirow{2}{*}{ Renal failure } & $0.421 * * *$ & $0.366 * * *$ & $0.366 * * *$ \\
\hline & $(0.019)$ & $(0.019)$ & $(0.019)$ \\
\hline \multirow[t]{2}{*}{ Excessive smoking } & $-0.545^{* * *}$ & $-0.473 * * *$ & $-0.476 * * *$ \\
\hline & $(0.042)$ & $(0.042)$ & $(0.042)$ \\
\hline \multirow[t]{2}{*}{ Hypertension } & $-0.591 * * *$ & $-0.568 * * *$ & $-0.566 * * *$ \\
\hline & $(0.016)$ & $(0.016)$ & $(0.016)$ \\
\hline \multirow[t]{2}{*}{ Vascular disease } & $-0.413 * * *$ & $-0.410 * * *$ & $-0.409 * * *$ \\
\hline & $(0.030)$ & $(0.030)$ & $(0.030)$ \\
\hline \multirow[t]{2}{*}{ Peripheral arterial disease } & -0.008 & -0.016 & -0.013 \\
\hline & $(0.025)$ & $(0.025)$ & $(0.025)$ \\
\hline \multirow[t]{2}{*}{ Stroke } & $0.352 * * *$ & $0.291 * * *$ & $0.293 * * *$ \\
\hline & $(0.025)$ & $(0.025)$ & $(0.025)$ \\
\hline \multirow[t]{2}{*}{ History of coronary artery disease } & $-0.217 * * *$ & $-0.231 * * *$ & $-0.228 * * *$ \\
\hline & $(0.030)$ & $(0.030)$ & $(0.030)$ \\
\hline \multirow[t]{2}{*}{ Heart failure } & $0.101^{* * *}$ & $0.057^{* * *}$ & $0.058 * * *$ \\
\hline & $(0.014)$ & $(0.014)$ & $(0.014)$ \\
\hline \multirow[t]{2}{*}{ Conduction disease } & $0.910 * * *$ & $0.889 * * *$ & $0.886 * * *$ \\
\hline & $(0.013)$ & $(0.013)$ & $(0.013)$ \\
\hline Location unknown or not reported & $<$ ref $>$ & $<$ ref $>$ & $<$ ref $>$ \\
\hline
\end{tabular}




$\begin{array}{lccc}\text { Anterior location } & -0.293^{* * *} & -0.203 * * * & -0.209 * * * \\ \text { Posterior location } & (0.017) & (0.017) & (0.017) \\ & -0.563 * * * & -0.462 * * * & -0.469 * * * \\ \text { Sub-endocardial } & (0.020) & (0.020) & (0.020) \\ & -1.030 * * * & -0.982 * * * & -0.982 * * * \\ \text { Other location } & (0.028) & (0.028) & (0.028) \\ & -0.530 * * * & -0.455^{* * *} & -0.458^{* * *} \\ & (0.027) & (0.027) & (0.027)\end{array}$

Note: ***: significant at 1\% level; **: significant at 5\% level; *: significant at $10 \%$ level. Estimated coefficients for age $\mathrm{x}$ sex dummies and treatments are reported in Table 3. 
Table A.2: Cox model including dummies for hospital status, propensity to die

\begin{tabular}{|c|c|c|c|}
\hline Explanatory variables & Age, sex, diagnoses & $\begin{array}{c}\text { Age, sex, } \\
\text { diagnoses, catheter }\end{array}$ & $\begin{array}{c}\text { Age, sex, } \\
\text { diagnoses, and all } \\
\text { procedures }\end{array}$ \\
\hline Catheter & & $-0.923 * * *$ & \\
\hline (possibly with dilatation or stent) & & (0.019) & \\
\hline \multirow[t]{2}{*}{ Catheter alone } & & & $-1.175 * * *$ \\
\hline & & & $(0.030)$ \\
\hline \multirow[t]{2}{*}{ Catheter with dilatation } & & & $-0.549 * * *$ \\
\hline & & & $(0.038)$ \\
\hline \multirow[t]{2}{*}{ Catheter with dilatation and stent } & & & $-0.848 * * *$ \\
\hline & & & $(0.025)$ \\
\hline For-profit hospital & $<$ ref $>$ & $<$ ref $>$ & $<$ ref $>$ \\
\hline \multirow[t]{2}{*}{ University hospital } & -0.026 & $-0.049 * *$ & $-0.057 * * *$ \\
\hline & $(0.021)$ & $(0.021)$ & $(0.021)$ \\
\hline \multirow[t]{2}{*}{ Non-teaching public hospital } & $0.103 * * *$ & $-0.139 * * *$ & $-0.130 * * *$ \\
\hline & $(0.018)$ & $(0.018)$ & $(0.018)$ \\
\hline Year dummies & $\mathrm{x}$ & $x$ & $x$ \\
\hline Age-and-sex dummies & $\mathrm{x}$ & $\mathrm{x}$ & $\mathrm{x}$ \\
\hline $\begin{array}{l}\text { Secondary diagnoses and comorbidities } \\
\text { dummies }\end{array}$ & $x$ & $\mathrm{x}$ & $\mathrm{x}$ \\
\hline Number of observations & 325,760 & 325,760 & 325,760 \\
\hline Number of deaths & 25,964 & 25,964 & 25,964 \\
\hline
\end{tabular}


Table A.2: Probit model of treatment with catheter (possibly with angioplasty and stent), By hospital status

\begin{tabular}{|c|c|c|}
\hline Variable & $\begin{array}{c}\text { Non- } \\
\text { teaching } \\
\text { public }\end{array}$ & For-profit \\
\hline Year 1998 & $<$ ref $>$ & $<$ ref $>$ \\
\hline Year 1999 & $\begin{array}{c}0.054^{* * *} \\
(0.013)\end{array}$ & $\begin{array}{c}0.109 * * * \\
(0.019)\end{array}$ \\
\hline Year 2000 & $\begin{array}{c}0.131^{* * *} \\
(0.012)\end{array}$ & $\begin{array}{c}0.219 * * * \\
(0.019)\end{array}$ \\
\hline Year 2001 & $\begin{array}{c}0.203^{* * *} \\
(0.012)\end{array}$ & $\begin{array}{c}0.313 * * * \\
(0.019)\end{array}$ \\
\hline Year 2002 & $\begin{array}{c}0.259 * * * \\
(0.012)\end{array}$ & $\begin{array}{c}0.285 * * * \\
(0.019)\end{array}$ \\
\hline Year 2003 & $\begin{array}{c}0.324 * * * \\
(0.012)\end{array}$ & $\begin{array}{c}0.154 * * * \\
(0.019)\end{array}$ \\
\hline Female, age $35-60$ & $<$ ref $>$ & $<$ ref $>$ \\
\hline Female, $60-70$ year old & $\begin{array}{c}-0.205^{* * *} \\
(0.024)\end{array}$ & $\begin{array}{c}-0.138 * * * \\
(0.040)\end{array}$ \\
\hline Female, $70-80$ year old & $\begin{array}{c}-0.465^{* * *} \\
(0.021)\end{array}$ & $\begin{array}{c}-0.394 * * * \\
(0.035)\end{array}$ \\
\hline Female, more than 80 year old & $\begin{array}{c}-1.282 * * * \\
(0.022)\end{array}$ & $\begin{array}{c}-1.148 * * * \\
(0.035)\end{array}$ \\
\hline Male, $35-60$ year old & $\begin{array}{c}0.066 * * * \\
(0.019)\end{array}$ & $\begin{array}{c}0.049 \\
(0.033)\end{array}$ \\
\hline Male, $60-70$ year old & $\begin{array}{c}-0.107^{* * *} \\
(0.020)\end{array}$ & $\begin{array}{c}-0.075^{* *} \\
(0.034)\end{array}$ \\
\hline Male, $70-80$ year old & $\begin{array}{c}-0.358 * * * \\
(0.020)\end{array}$ & $\begin{array}{c}-0.240 * * * \\
(0.034)\end{array}$ \\
\hline Male, more than 80 year old & $\begin{array}{c}-1.011^{* * *} \\
(0.022)\end{array}$ & $\begin{array}{c}-0.867 * * * \\
(0.036)\end{array}$ \\
\hline Alcohol problems & $\begin{array}{c}-0.371 * * * \\
(0.030)\end{array}$ & $\begin{array}{c}-0.242 * * * \\
(0.053)\end{array}$ \\
\hline Diabetes & $\begin{array}{c}-0.048 * * * \\
(0.010)\end{array}$ & $\begin{array}{c}-0.025 * \\
(0.015)\end{array}$ \\
\hline Obesity & $\begin{array}{c}0.095 * * * \\
(0.015)\end{array}$ & $\begin{array}{c}0.259 * * * \\
(0.022)\end{array}$ \\
\hline Renal failure & $-0.147 * * *$ & $-0.196 * * *$ \\
\hline
\end{tabular}




\begin{tabular}{|c|c|c|}
\hline Excessive smoking & $\begin{array}{c}0.097^{* * *} \\
(0.011)\end{array}$ & $\begin{array}{c}0.414 * * * \\
(0.019)\end{array}$ \\
\hline Hypertension & $\begin{array}{c}0.122^{* * *} \\
(0.008)\end{array}$ & $\begin{array}{c}0.223 * * * \\
(0.012)\end{array}$ \\
\hline Vascular disease & $\begin{array}{c}-0.190 * * * \\
(0.021)\end{array}$ & $\begin{array}{c}-0.130 * * * \\
(0.021)\end{array}$ \\
\hline Peripheral arterial disease & $\begin{array}{c}0.167^{* * *} \\
(0.015)\end{array}$ & $\begin{array}{l}-0.019 \\
(0.020)\end{array}$ \\
\hline Stroke & $\begin{array}{c}-0.220 * * * \\
(0.022)\end{array}$ & $\begin{array}{c}-0.135^{* * *} \\
(0.029)\end{array}$ \\
\hline History of coronary artery disease & $\begin{array}{c}-0.179 * * * \\
(0.020)\end{array}$ & $\begin{array}{c}-0.089 * * * \\
(0.023)\end{array}$ \\
\hline Heart failure & $\begin{array}{c}-0.220 * * * \\
(0.011)\end{array}$ & $\begin{array}{c}-0.212^{* * *} \\
(0.016)\end{array}$ \\
\hline Conduction disease & $\begin{array}{c}-0.080 * * * \\
(0.009)\end{array}$ & $\begin{array}{c}-0.175^{* * *} \\
(0.014)\end{array}$ \\
\hline Location unknown or not reported & $<$ ref $>$ & $<$ ref $>$ \\
\hline Anterior location & $\begin{array}{c}0.134 * * * \\
(0.010)\end{array}$ & $\begin{array}{c}0.253^{* * *} \\
(0.017)\end{array}$ \\
\hline Posterior location & $\begin{array}{c}0.149 * * * \\
(0.010)\end{array}$ & $\begin{array}{c}0.298 * * * \\
(0.017)\end{array}$ \\
\hline Sub-endocardial & $\begin{array}{c}0.003 \\
(0.013)\end{array}$ & $\begin{array}{c}0.066 * * * \\
(0.021)\end{array}$ \\
\hline Other location & $\begin{array}{c}0.054 * * * \\
(0.014)\end{array}$ & $\begin{array}{c}0.109 * * * \\
(0.022)\end{array}$ \\
\hline CABG or Coronary Bypass surgery & $\begin{array}{c}-0.322^{*} \\
(0.170)\end{array}$ & $\begin{array}{c}-0.979 * * * \\
(0.041)\end{array}$ \\
\hline Constant & $\begin{array}{c}-0.512^{* * *} \\
(0.006)\end{array}$ & $\begin{array}{c}0.589 * * * \\
(0.011)\end{array}$ \\
\hline Number of observations & 164779 & 68272 \\
\hline Pseudo-R2 & 0.116 & 0.135 \\
\hline
\end{tabular}

Note: ***: significant at $1 \%$ level; **: significant at 5\% level; *: significant at $10 \%$ level. 
Figure A.1: Probability of death as a function of duration (in days), from a model including age $\mathrm{x}$ sex, secondary diagnoses, comorbidities and catheter Bootstrapped confidence intervals

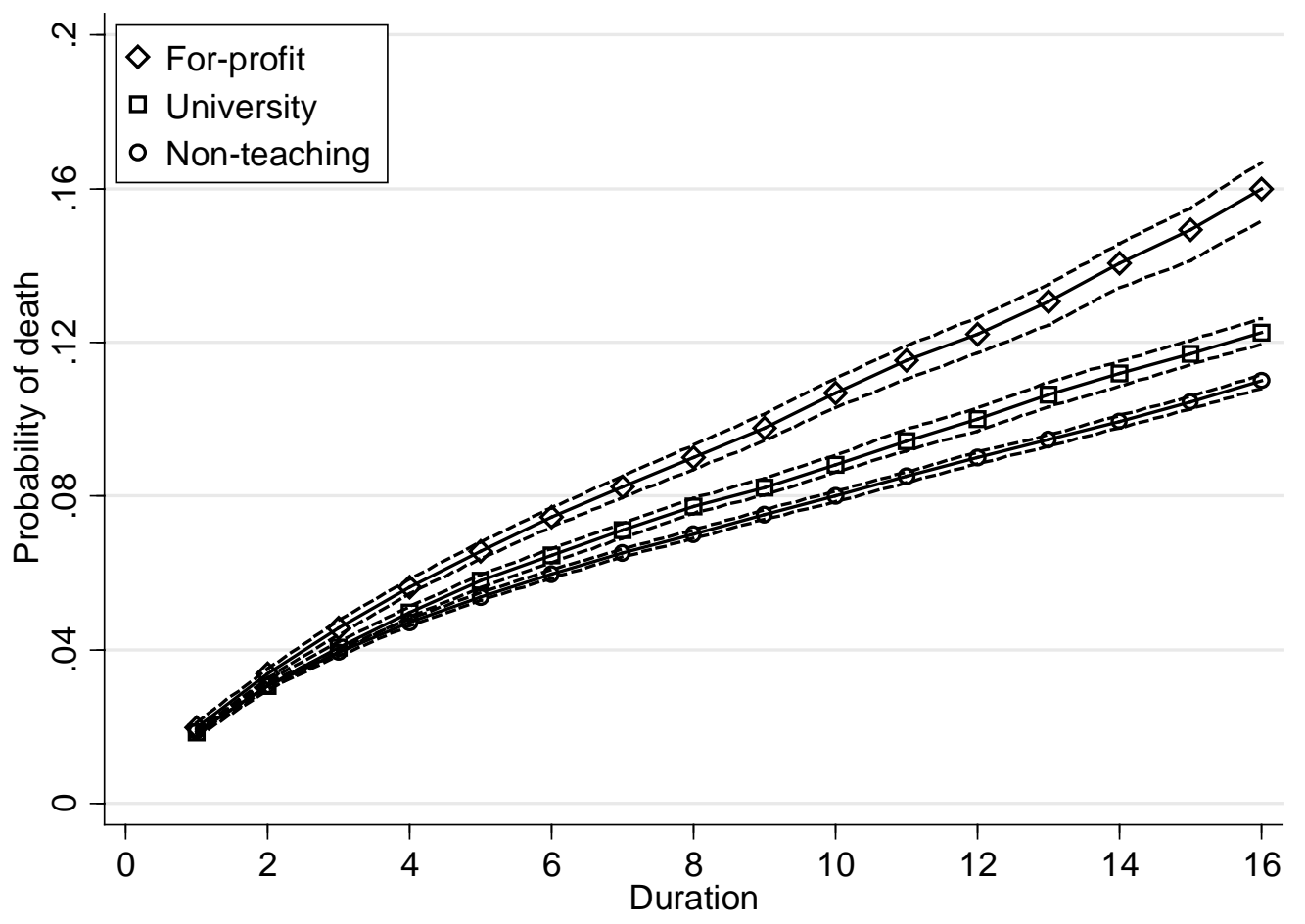

Note: for a given hospital status, an aggregate probability of death is computed as a weighted average of the estimated probabilities of death for hospitals with that status (each probability of death being obtained as the exponential of minus the Breslow estimator of the integrated hazard for a patient with the average effect of individual variables), where the weight is the number of patients admitted to each hospital. The probability of death at $t$ days is thus the probability that the patient has died within the first t days. Confidence intervals are bootstrapped using 100 replications. 